\title{
SUPPORT FOR REDISTRIBUTION IN AN AGE OF RISING INEQUALITY: NEW STYLIZED FACTS AND SOME TENTATIVE EXPLANATIONS
}

\author{
Vivekinan Ashok \\ Ilyana Kuziemko \\ Ebonya Washington \\ Working Paper 21529 \\ http://www.nber.org/papers/w21529
NATIONAL BUREAU OF ECONOMIC RESEARCH
1050 Massachusetts Avenue
Cambridge, MA 02138
September 2015

We thank Angus Deaton, David Romer, Joanna Lahey, Matt Weinzierl, Justin Wolfers, seminar participants at Princeton and discussants Peter Enns and Paola Guiliano for incredibly helpfulfeedback. Khurram Ali and María Bernardita Canals Cavagnaro provided invaluable research assistance. This paper was prepared for the 2015 spring Brookings Papers on Economic Activity. The views expressed herein are those of the authors and do not necessarily reflect the views of the National Bureau of Economic Research.

NBER working papers are circulated for discussion and comment purposes. They have not been peerreviewed or been subject to the review by the NBER Board of Directors that accompanies official NBER publications.

(C) 2015 by Vivekinan Ashok, Ilyana Kuziemko, and Ebonya Washington. All rights reserved. Short sections of text, not to exceed two paragraphs, may be quoted without explicit permission provided that full credit, including (C) notice, is given to the source. 
Support for Redistribution in an Age of Rising Inequality: New Stylized Facts and Some Tentative Explanations

Vivekinan Ashok, Ilyana Kuziemko, and Ebonya Washington

NBER Working Paper No. 21529

September 2015

JEL No. D63,H23,J14,J15

\begin{abstract}
Despite the large increases in economic inequality since 1970, American survey respondents exhibit no increase in support for redistribution, in contrast to the predictions from standard theories of redistributive preferences. We replicate these results but further demonstrate substantial heterogeneity by demographic groups. In particular, the two groups who have most moved against income redistribution are the elderly and African-Americans. We find little evidence that these subgroup trends are explained by relative economic gains or growing cultural conservatism, two common explanations. We further show that the elderly trend is uniquely American, at least relative to other developed countries with comparable survey data. While we are unable to provide definitive evidence on the cause of these two groups' declining redistributive support, we offer additional correlations which may offer fruitful directions for future research on the topic. One story consistent with the data on elderly trends is that older Americans worry that redistribution will come at their expense, in particular via cuts to Medicare. We find that the elderly have grown increasingly opposed to government provision of health insurance and that controlling for this tendency explains about $40 \%$ of their declining support for redistribution. For blacks, controlling for their declining support of race-targeted aid explains nearly $45 \%$ of their differential decline in redistributive preferences (raising the question of why support for race-targeted aid has fallen during a period when black economic catch-up to whites has stalled).
\end{abstract}

Vivekinan Ashok

Yale University

Department of Political Science

P.O. Box 208301

New Haven, CT 06520-8301

vivekinan.ashok@yale.edu

Ilyana Kuziemko

Department of Economics

Princeton University

322 Wallace Hall

Princeton, NJ 08544

and NBER

kuziemko@princeton.edu
Ebonya Washington

Yale University

Box 8264

37 Hillhouse, Room 36

New Haven, CT 06520

and NBER

ebonya.washington@yale.edu 


\section{Introduction}

Since the 1970s the United States has witnessed two trends whose coexistence calls into question predictions from standard political economy models (e.g., Meltzer and Richard, 1981). As documented extensively in Piketty and Saez (2003) as well as their annual updates, the U.S. income distribution has grown substantially more concentrated since the 1970s. As Figure 1 shows, the share of income accruing to the top one percent more than doubled between 1978 and 2007. ${ }^{1}$ The growth of inequality has not been limited to the top "one percent" but also appears in broader distributional measures (Autor, 2014).

The workhorse political economy model suggests that an individual's demand for redistribution is a function of mean income minus own income. As inequality increases, a greater share of the population has income below the mean and thus demand for redistribution rises. Yet, in reality, demand for income redistribution in the US has remained flat by some measures and decreased for others (see, e.g., Kuziemko et al. (2013), and we further document this fact later in the paper). Beyond the US, citizens of other OECD countries that have seen rising income inequality have generally not exhibited greater demand for redistribution (Kenworthy and McCall, 2008).

Explaining this puzzle has inspired a large literature, ranging from racial politics to belief in upward mobility. ${ }^{2}$ Our goal in this paper is not to offer a new explanation. Instead, we offer new "clues" to the puzzle by delving deeper into the U.S. survey data, as well as comparing it to trends from other developed countries. Our hope is that future work trying to explain the evolution of redistributive preferences would try to fit the new stylized facts we establish in this study.

In the first part of the paper, we replicate past work showing that trends in the demand for redistribution among Americans has been largely flat or perhaps slightly negative over this period. We show that this result is robust across different redistributive questions as well as different datasets.

We then document (for the first time to our knowledge) the great heterogeneity in trends for support for redistribution during this time period. We focus on "immutable" demographic characteristics, so as to put aside worries about compositional changes. Two groups - the elderly and African-Americans - have significantly decreased their support for redistribution, relative to other respondents. While race and age differences are pronounced and robust in

\footnotetext{
${ }^{1}$ See their online updates at http://eml.berkeley.edu/ saez/TabFig2012prel.xls.

${ }^{2}$ See, e.g., Lee and Roemer (2006), Benabou and Ok (2001), and citations therein.
} 
the data, we do not find significant gender differences in trends in redistributive preferences.

The second part of the paper explores potential explanations for our two heterogeneity results: the relative decline in redistributive support among the elderly and African Americans. We begin with the standard model of economic self-interest: have these groups made relative gains in income or other measures of economic well-being?

In fact, we make little progress explaining these subgroup trend divergences with economic and even broader well-being measures. One exception is that educational gains (perhaps acting as a proxy for permanent income) can explain roughly $30 \%$ of the differential elderly trend (though it remains negative and statistically significant). Otherwise, household income, perceived place in the income distribution, perceived social class, self-reported health and subjective well-being and perceived inter- and intra-generational mobility do little to "explain away" the relative decline in redistributive support among the elderly and blacks.

A more psychological model of redistributive preferences emphasizes the role of cognitive dissonance - if an individual becomes more conservative on social issues (e.g., abortion), she might also become more economically conservative so as to remain consistent in an ideological or partisan sense. ${ }^{3}$ We thus subject our differential trend results to a variety of partisan and ideological controls, as well as control for views on particular hot-button issues: religious attendance, abortion, gay rights and gun rights. We find little evidence that a general rightward movement ideologically or culturally among the elderly or blacks has dragged redistributive views to the right.

Having failed to explain our divergent trends with common models of redistributive preferences, we attempt explanations drawn from the particular historical or institutional features specific to each of these groups. The U.S. elderly have enjoyed tremendous gains in life expectancy and years of retirement, which our self-reported health and other wellbeing measures may not capture. These gains have generally been enjoyed by the elderly across the OECD. To the extent that these broad trends can explain the decline in the elderly's support for redistribution, we should see the same results elsewhere. In fact, in every developed country where comparable data have been collected, the elderly's support for redistribution follows either a parallel trend to the rest of adults, or is differentially increasing. Thus, the decline we find among the elderly appears exclusively American.

This international evidence leads us to explore whether there exist aspects of U.S redistributive policy that, relative to other countries, are unique in the treatment of the elderly.

\footnotetext{
${ }^{3}$ The classic citation on cognitive dissonance is Festinger (1957) but we review the more modern literature and in particular its connection to partisan identity later in the paper.
} 
The most obvious candidate is that in the US, the government guarantees health insurance for only one immutable group: the elderly, whereas this coverage is universal in other developed countries. As Campbell (2003) has noted, the threat of Medicare cuts politically energizes U.S. seniors. We find evidence that this view may be driving elderly views on redistribution: seniors have grown increasingly opposed to extending the government guarantee of health coverage and controlling for this changing view explains nearly $40 \%$ of the elderly's relative decline in redistributive support.

Finally, to explain the declining support for redistribution among blacks, we are motivated by the large literature showing that those who believe economic outcomes are the result of a fair process are more opposed to redistribution. In surveys, blacks are far less likely than whites to agree that economic outcomes are fair, not surprising given the legacy of slavery and segregation. And perhaps as a result blacks are far more likely to support race-based government aid. We show, however, that over the past several decades blacks have moved significantly toward the white view on these questions. In particular, controlling for views on race-based government aid explains nearly half of the decline in black redistributive preferences. We are thus able to provide a proximate determinant of the decline in black redistributive preferences, which only raises the question of why blacks' support for racebased aid has fallen during a period when their economic catch-up to whites has stalled.

The remainder of the paper proceeds as follows. In Section 1 we replicate past findings on the flat trend in overall redistributive demand in the US over the past several decades, as well as establish new facts on heterogeneity by demographic subgroup. In Section 2 we explore how well standard models do in explaining these divergent subgroup results. In Section 3 we explore hypotheses specific to the elderly and in Section 4 we do the same for blacks. In Section 5 we offer concluding thoughts and suggests areas for future work.

\section{Trends in redistributive demand}

While aggregate demand for redistribution has not increased over this period of rising inequality, in this section we document substantial heterogeneity in this pattern across subgroups. To ensure that our heterogeneous patterns are not driven by data or coding differences between our paper and previous work, we first demonstrate that we can replicate the earlier finding of flat aggregate demand using our survey measures. 


\subsection{Aggregate trends in redistributive demand}

We have identified four questions on redistribution that have been fielded regularly since the 1970s. Our first and focal question is drawn from our primary dataset the General Social Survey, a representative survey of American households. The GSS asks, "Some people think that the government in Washington ought to reduce the income differences between the rich and the poor, perhaps by raising the taxes of wealthy families or by giving income assistance to the poor. Others think that the government should not concern itself with reducing this income difference between the rich and the poor. Here is a card with a scale from 1 to 7 . Think of a score of 1 as meaning that the government ought to reduce the income differences between rich and poor, and a score of 7 meaning that the government should not concern itself with reducing income differences. What score between 1 and 7 comes closest to the way you feel?." We subtract this variable from eight so that it is increasing in support for redistribution and refer to it as the "reduce differences" variable. It is our preferred measure because it specifically mentions differences between the rich and the poor, whereas the other measures focuses more on the poor.

Figure 2(a) shows a scatterplot, with best-fit lines, of mean response to the "reduce differences" question over time. ${ }^{4}$ We present two best fit lines in this graph and those that follow. The longer is the fit through all years for which we have data. The shorter line, our preferred estimate, is the best fit through 2006 (the last time the question is asked in the pre-Great Recession period).

We prefer to restrict attention to this shorter period for at least four reasons. First, inequality did not actually increase during the Great Recession, as shown in Figure 1, by 2012 (the most recent year available) the top one percent had yet to regain the steep losses to their income share incurred in 2008 and 2009. Second, this period also witnessed the greatest downturn since the Great Depression, which likely has its own effect on redistributive demand. Third, as we are interested in trends by race, including the administration of the first black president might well conflate racial attitudes with view of government and thus not reflect views about redistribution per se. Finally, we wish to hold the redistributive policy

\footnotetext{
${ }^{4}$ Throughout the paper we weight samples using the provided survey weights. In the GSS, to include those respondents from years in which over-samples were conducted, we use the product of the wtssall and oversamp variables as our weight. Toward the end of our sample period, the GSS introduces interviews in Spanish (before that time, respondents who could not complete an English-language version of the survey were excluded). To keep the sample consistent, we drop those who the GSS deems would have been unable to have taken the interview if it were not in Spanish $($ spanint $=2)$.
} 
landscape fairly constant. Leonhardt (2015) described the Affordable Care Act of 2010 as "the most aggressive attack that the federal government has launched against inequality since inequality began rising four decades ago." To the extent we wish to offer clues to the puzzle of why demand for redistribution did not increase despite rising inequality, it seems prudent to exclude these most recent years, in which the economic and policy environment changed dramatically, inequality did not increase on net and which, coming at the end of the time-series, will greatly influence trend lines.

Both fitted lines depicts a slight decrease in demand for redistribution, at least as reflected by this variable. Measured against the left-hand axis, the drop is about $10 \%$ of a point on the seven-point "reduce differences" scale. Because the seven-point scale has no intuitive interpretation, we also measure the drop in "partisan units." That is, we normalize the measure so that zero represents the view of the average respondent over the sample period, and an increase of one unit for this variable is equal to moving the distance between the average Republican's views and the average Democrat's view on this question. ${ }^{5}$ Partisan units are marked on the right-hand axis. Additionally, the -.0042 [.0033] label on the graph refers to the slope and standard error of the shorter best fit line in "partisan units"; these numbers indicate that across the 28 year sample period (1978 to 2006) Americans have moved $(0.0042 \cdot 28)$ nearly $12 \%$ of the Democrat-Republican difference on this question, a movement that is statistically insignificant. Like previous literature, we cannot reject that the trend is flat despite the standard model's prediction of rising support given the increasing inequality of this time period.

This absence of increasing demand for redistribution is robust across all of our alternative measures of redistributive support. The second question we have identified, also from the GSS, asks, "Some people think that the government in Washington should do everything possible to improve the standard of living of all poor Americans.... Other people think it is not the government's responsibility, and that each person should take care of himself." Respondents are asked to place themselves on a five point scale along the described continuum, which we again flip to be increasing in redistributive support. As shown in Figure 2(b), by this measure Americans have seen an even greater decline - more than 0.3 partisan points - in support for redistribution over both our focal and expanded time periods.

Our third question is on the role of government. The GSS asks, "Some people think

\footnotetext{
${ }^{5}$ The GSS asks individuals to rank themselves 1-7 on a Republican-Democrat scale, with 4 being "independent." We calculate the difference in the outcome variable between those answering 1-3 (Republican) and those answering 5-7 (Democrat). We then divide the variable by this difference.
} 
that the government in Washington is trying to do too many things that should be left to individuals and private businesses. Others disagree and think that the government should do even more to solve our country's problems." Respondents indicate their place along this continuum on a one to five scale. We recognize that this question is less directly related to redistribution than are the first two, but show the results for the sake of robustness. As shown in Figure 2(c), during this period of increased inequality, Americans have not increased in their desire for government intervention.

Our final measure of redistributive preferences comes from the American National Election Studies (ANES), a representative sample of voting-age Americans. ANES asks "Some people feel that the government in Washington should see to it that every person has a job and a good standard of living.... Others think the government should just let each person get ahead on his/their own." Respondents place themselves on a seven-point scale on this continuum, which we flip so that it is increasing in redistributive support. We plot the result in Figure 2(d). While the sign of the ANES results differs from that using the various GSS measures, like our main GSS outcome, it is essentially flat. ${ }^{6}$ Across the four measures, we are able to replicate the finding of previous literature of no increase in support for redistribution over this period of increased inequality. As we noted from the onset, this lack of increased support is puzzling. In an effort to provide clues for solving this puzzle, in the next section we demonstrate, we believe for the first time, that these aggregate trends mask substantial heterogeneity across demographic groups.

\subsection{Trends by subgroup}

In this section we examine how the trend in support for redistribution varies by immutable demographic subgroups: age, race and sex.

\subsubsection{Trends by age}

In Figure 3(a) we return to our focal GSS "reduce differences" question and demonstrate remarkable heterogeneity in the trends of younger and older respondents. Over our 28 year sample period, while those under 65 saw no significant change in mean desire for the reduction of income inequality, those aged 65 or older grew increasingly negative toward redistribution. Looking at our standardized party scale on the right-hand axis, we see that across our

\footnotetext{
${ }^{6}$ Our last ANES datapoint is 2008. The question is fielded again in 2012, but at the time of analysis only preliminary data were available for that wave.
} 
sample period, the elderly decreased their support by more than $50 \%$ of the DemocratRepublican difference. This relative decrease among the elderly is robust to using our ANES redistribution question (Figure 3b). By this measure young Americans have seen a marginally significant increase of about $20 \%$ of a partisan unit over the 36 year sample period, while the elderly show a significant decline of roughly $40 \%$ of the party difference over the time period. By either measure, the relative position of the elderly has flipped; the group begins the time period more in favor of redistribution than the rest of the population (significantly so in the GSS), but end the time series significantly less supportive (both for the GSS and the ANES).

\subsubsection{Trends by race}

The second demographic split we investigate is race. Because of sample size limitations, we are able to examine only two racial groups: blacks and whites. ${ }^{7}$ Like with age, we demonstrate in Figure 3 remarkable differences in trends by race in both the GSS (subfigure c) and the ANES (subfigure d). While there has been no significant movement on the issue by whites, in both datasets, blacks, who have a much higher desire for redistribution on average, have significantly decreased their support, by nearly half of a partisan unit in the GSS and about $90 \%$ of a unit in the ANES, over their respective sample periods.

\subsubsection{Trends by gender}

Unlike for race and age, we do not find significant trend differences by gender in either dataset. In both the GSS and the ANES, we see that women have a higher demand for redistribution than men and the sexes trend similarly-decreasing (increasing) in support in the GSS (ANES) - over time (See Figure 4). This non-result is somewhat surprising given the large income gains women have made relative to men over the same time period.

\subsection{Discussion}

While Americans overall have exhibited no marked trend in their support for redistribution over the past four decades, our subgroup analyses have identified two groups with markedly negative trends over time: the elderly and African-Americans. These groups are in fact among

\footnotetext{
${ }^{7}$ Moreover, the GSS only asks about Hispanic ethnicity consistently beginning in 2000 .
} 
the most dependent on transfers, making their redistributive trends a priori surprising. ${ }^{8}$ In the next section, we explore whether commonly used models of redistributive preferences may explain the divergent trends of these two subgroups.

\section{Can standard models of redistributive preferences explain sub- group trends}

In this section, we explore to what extent we can "explain away" the black and elderly differential trends that we uncovered in the previous section, using controls suggested by common models of redistributive preferences.

\subsection{Economic self-interest}

The workhorse political economy model has voters maximizing after-tax income, with demand for redistribution an increasing function of the difference between their income and that of the average tax-payer. We thus begin our exploration of why the elderly and AfricanAmericans have differentially moved against redistribution by examining the robustness of their differential trends to a myriad of income controls. As we tend to prefer the main GSS redistribution question (i.e., our "reduce differences" question), we focus on that data source in the analysis that follows, though all results are robust to using the ANES and for some key results we will report the parallel ANES analysis.

Col. (1) of Table 1 quantifies the relative decline among the elderly in support for redistribution, essentially replicating the first panel (shorter time period, through 2006) of Figure 3 in regression form. With no controls besides the Elderly dummy and year fixed effects, the elderly (relative to others) decrease their answer to this question by roughly 0.20 points (on a seven-point scale) per year. Again, as the units of this coefficient have no intuitive interpretation, below the table we provide two alternative measures of the magnitude of our findings. First, we divide the coefficient by the variable's standard deviation and report it as the "scaled effect (SD)". Second, we divide the coefficient by the Democrat-Republican difference on this question, and report it as the "scaled effect (party)" below the coefficient estimate. As the coefficient is in terms of 100 years whereas our GSS sample period typically

\footnotetext{
${ }^{8}$ Between 1978 and 2006, the average share of total income coming from government transfers for the elderly was approximately $65 \%$; as opposed to roughly $10 \%$ for the non-elderly. Similarly, over the same period, the average share for African Americans was about 25\%; as opposed to around $15 \%$ for whites. Authors' calculations using CPS data.
} 
spans 28 years (depending on the outcome question), the "scaled effect" listed in col. (1) suggests that over this period, the elderly have differentially shifted their views on this question by roughly $29 \%$ of a standard deviation $(0.28 \cdot 1.023)$, or by an amount equal to roughly fifty percent $(1.846 \cdot 0.28)$ of the partisan gap on this question (moving in the "Republican" direction).

Col. (5) shows the parallel analysis for blacks. The coefficient of interest suggests that over our 28-year sample period, relative to other groups, black support for redistribution has moved $22 \%$ of a standard deviation or a distance equal to $37 \%(1.316 \cdot 0.28)$ of the Democrat-Republican gap on this question (again, in the Republican direction), consistent with Figure 3(c).

In columns (2) and (6) we add household income controls. We use the GSS realinc measure, converted to 2014 dollars, and adjust for household size as in Stevenson and Wolfers (2013). We also have a separate control for the roughly ten percent of respondents who have missing information for this variable. Below the coefficient estimates, we report the "share explained" (merely one minus the coefficient of interest after we include controls divided by the original coefficient). For both groups, controlling for household income has essentially no effect on the coefficient of interest. For the elderly, the income controls "explain" roughly four percent of the original effect. For blacks, including income controls actually increases the magnitude of the group's differential trend, though, again, in both cases the effect is close to zero.

Especially for the elderly (many of whom are retired), actual income may be a noisy proxy for economic well-being, and thus in cols. (3) and (7) we use education (fixed effects for highest degree attained) as a proxy for permanent income. For the elderly (col. 3), this control has some explanatory power, reducing the original coefficient by nearly $30 \%$ (though the elderly differential trend remains negative and highly significant). In col. (7), controlling for education once again increases (very slightly) the black differential trend.

The controls we have used so far are based on respondents' assessments of absolute, objective measures. In the final set of analyses in Table 1 we control for more subjective and relative measures: where the respondent places her household in the U.S. income distribution relative to the average household (fixed effects for far below, below, average, above and far above) and which class she sees herself in (lower, working, middle or upper). For neither group do these controls go far in explaining different trends. The controls serve to reduce the elderly coefficient by less than $15 \%$ and the black coefficient by less than $10 \%$. 
We perform a number of robustness checks related to the results in Table 1. First, we demonstrate that the elderly and black trends (cols 1 and 4) are robust to controlling for each other simultaneously as well as simultaneously controlling for female $\times$ year, top income quintile $\times$ year, college $\times$ year (see Online Appendix Table A.1). As such, the black and elderly trends appear to be separately identifiable phenomena and separate from any other groups' trend.

While we noted earlier that our preferred sample period excludes the Great Recession years, in Online Appendix Table A.2 extend our sample period through 2012. While heterogeneity by age is greater over the longer time frame, the race gap shrinks substantially and is no longer statistically significant when we include the period confounded by the Great Recession, the first black president and the passage of the Affordable Care Act. However, the limited ability of covariates to explain the basic trends holds true for both groups in this extended period.

In Online Appendix Table A.3 we show that the results of cols 2-5 and 6-8 in Table 1 are robust to interacting each of these economic controls with the main effect (elderly or black, depending on the specification). These specifications allow the controls to have different effects on redistributive preferences across our key groups. In fact, this flexibility tends to have less explanatory power in terms of explaining the differential trends among blacks, and thus the differential trends that remains tend to grow using this specification.

To maximize sample size, we create a separate category for observations with missing household income values, but Online Appendix Table A.4 shows that our results hold if we instead drop these observations. Finally, while we will use OLS for ease of interpretation, in Online Appendix Table A.5 we show that our results are robust to using an ordered probit model. In fact, the cut-points generated by the ordered probit model are very close to linear (Online Appendix Figure A.1), suggesting OLS is a reasonable estimating model.

Besides probing the specifications and regression samples used in Table 1, in Table 2 we also explored whether broader measures of well-being, economic or otherwise, might better explain the differential trends of the elderly and blacks. For ease of comparison (and because some questions are only asked in a subset of sample years) each odd numbered column provides the baseline elderly or black specification with no additional controls on the subsample of observations with non-missing responses to the controls used in the even numbered column that follows. In Cols. (2) and (8) the control is self-reported happiness, which fails to explain the elderly trend at all, but does lead to a small (ten percent) reduction in the black dif- 
ferential trend (though it remains highly significant), consistent with Stevenson and Wolfers (2013) findings on black-white happiness convergence. Given the large life-expectancy gains to the elderly (a topic to which we return briefly in Section 3) we control for self-assessed health in cols. (4) and (10), which reduces the elderly and black coefficients by only eight and two percent respectively.

Finally, in cols. (6) and (12) we explore the explanatory power of views on intergenerational mobility, which past authors have found reduces support for redistribution. ${ }^{9}$ Specifically, we control for whether the respondent thinks that her children's standard of living will be worse than her own and whether she feels that her standard of living is worse than her parents (we drop childless respondents). Only the latter control significantly correlates with redistributive preferences. The inclusion of both mobility variables serves to increase our key coefficients slightly. While we do not have intragenerational questions in the GSS, the ANES asks whether the respondent believes that she will be better off next year. That variable's inclusion does not change the black and elderly differential trends significantly (results available upon request). ${ }^{10}$

\subsection{Increased conservatism and cognitive dissonance}

A second hypothesis that we explore is that the declines in redistributive support among the elderly and blacks are part of a larger trend of increased conservatism amongst these groups. Kelly and Enns (2010), find that increased income inequality is associated with increased conservatism. To the extent that this effect was differentially large for blacks and the elderly, these groups may have become relatively more conservative over time.

To explore the possibility of increasing conservatism more generally as a cause of increased conservatism in redistributive views, in Table 3 we examine the extent to which our differential trends by age (race) are "explained" by controls for conservatism. We recognize, however, that a significant correlation between redistributive attitudes and other attitudes could result from redistributive views as either cause or effect. Scholars have demonstrated the relevance of the theory of cognitive dissonance (Festinger, 1957) - which posits a need for internal consistency - to political views. (See for example Beasley and Joslyn, 2001, Mul-

\footnotetext{
${ }^{9}$ See Checchi et al. (1999) and Corneo and Grüner (2002) on the connection between intergenerational mobility and redistributive preferences.

${ }^{10}$ The classic treatment of redistributive demand as a function of personal mobility is Hirschman and Rothschild (1973). A more recent application with Russian data is Ravallion and Lokshin (2000).
} 
lainathan and Washington (2009) and Gerber et al. (2010).)

But in fact the results of Table 3 demonstrate that for neither blacks nor the elderly is the decline in redistributive support explained by a general movement toward conservatism. In column 1 (5) we repeat the basic uncontrolled age (race) specification for comparison. In cols. (2) and (6) we control for party identification (a one to seven scale running from strong Democrat through strong Republican). For both blacks and the elderly, controlling for party identification makes the magnitude of the differential redistributive trend even larger (15\% so in the case of blacks). As these coefficient patterns suggest, despite their movement away from redistribution, blacks and the elderly have become no more Republican (and in fact blacks have become, relatively speaking, significantly more Democratic, as whites have moved away from the party while blacks have remained loyal).

Cols. 3 and 7 show that, unlike party identification, controlling for political ideology (a seven-point scale from extremely liberal through extremely conservative) does decrease the coefficients of interest, but by a small amount (11\% for the elderly and under $3 \%$ for blacks). Finally, as Layman (1997) and others since have noted, religious attendance has become increasingly linked with conservatism, so in cols. (4) and (8) we add a nine-point scale of attendance (from never attend to more than weekly) as a control. As with political ideology, the effect on the coefficients of interest is very limited, although this time with a larger decrease for blacks (7\%) than for the elderly (under $2 \%$ ).

In a final test of the general conservatism hypothesis we explore how views on certain political "hot-button" issues - abortion, homosexuality and gun control - serve to explain our patterns. We relegate these results to Online Appendix Table A.6 because of loss of sample size. Nonetheless, like the more global attitudinal measures, these single issues explain less than 10 percent of our trends in redistributive views by age and race. We find no evidence that the decline in redistributive support for either blacks or the elderly is part of a wider trend toward ideological or cultural conservatism.

\subsection{Discussion}

In general, controls associated with common models of redistributive preferences have limited power to explain why the elderly and African-Americans have moved against redistribution, relative to other Americans. In the case of the elderly, we find some evidence that the standard model of economic self-interest may hold, as controlling for education (potentially a better proxy of permanent income for this largely retired population than current annual income) 
reduces the differential elderly trend by $30 \%$. For blacks, these standard controls enjoy even less success in reducing the magnitude of the coefficient of interest.

In the final two sections of the paper, we move beyond standard redistributive theories and instead explore whether historical or institutional factors specific to each of these groups can provide clues to their declining support for redistribution.

\section{Explanations specific to the elderly}

\subsection{Do unobserved changes to elderly wellbeing explain their trend?}

While we are able to observe and control for economic and attitudinal shifts among the elderly in our sample period, our controls perhaps imperfectly capture large, underlying trends for this group. Life expectancy over our sample period has significantly increased, and along with it the total years of retirement that individuals can expect to enjoy. Perhaps as a reaction, there have been increasing calls in policy circles to raise the age of eligibility for collecting government retirement benefits, which could affect the elderly's redistributive preferences.

In the United States, life expectancy for men (women) at age 65 increased from 13.2 (16.9) years in 1970 to 17.8 (20.4) in 2011. ${ }^{11}$ And, indeed those 65 and over reporting good or very good health between 1982 and 2011 grew from 65\% to 75\%. ${ }^{12}$ While we tried controlling for health in our regression analysis, we may not be fully capturing these gains in wellbeing, nor the effect of the corresponding policy pressure on retirement ages.

The parallel trends of increasing life expectancy at age 65 and the postponement of full retirement benefits generally hold across OECD countries. In this section we ask, is the relative decline in redistributive support among the elderly replicated in other developed countries?

\subsection{Comparing the elderly: international evidence}

The General Social Survey and the ANES are relatively unusual in providing the ability to examine several decades-long trends regarding redistributive preferences. Multi-country surveys such as the World Values Survey or the European Social Survey have only been fielded

\footnotetext{
${ }^{11}$ OECD (2015), Life expectancy at 65 (indicator). doi: 10.1787/0e9a3f00-en (Accessed on 08 March 2015)

${ }^{12}$ OECD Health Statistics (2015). doi: 10.1787/health-data-en (Accessed on 08 March 2015)
} 
three or four times (and in the case of the latter, only once before the 2008 economic crisis) and are thus of limited use for long-run trend analysis. To place our results for the American elderly in a comparative context we performed a comprehensive search of the survey data from 17 developed countries and found only three had similar data: the UK, Germany and Sweden. ${ }^{13}$ In all three cases the available span of years was more limited. While more data would have been ideal, these countries give us coverage from another Anglo-Saxon economy, as well as continental Europe and Scandinavia.

The immutability of age and the fact that all our case countries have state-run pension programs, allows us to examine elderly support for redistribution cross-nationally. Each of these countries has exhibited similar gains in life expectancy conditional on reaching the retirement age, and all but one (Sweden) have planned increases in their "pensionable ages." 14 As such, if these broad trends were causing the decline in the American elderly's redistributive preferences, we should see similar evidence abroad. We discuss the three data sources briefly before presenting the cross-national evidence.

\subsubsection{United Kingdom Data}

The British Social Attitudes (BSA) survey has been administered annually since 1983. Sampling aims to be representative of the British population and each year roughly 3,000 respondents are interviewed in their homes. Britain is an especially useful comparison to the US given its historical connections but also because the country has seen a marked rise in pre-tax income inequality (though somewhat smaller than the increase in the US) since the 1980s (Atkinson et al., 2011).

In roughly half of the years since 1983, the BSA has asked three questions related to redistributive preferences. The first asks whether the government should "reduce income differences." Respondents indicate their agreement with the idea on a five-point scale. The second asks about the gaps between high and low incomes ("too small" being coded as one, while "too large" coded as three). Finally, related to the first question, a third question asks whether "the government should redistribute income" and again gives respondents a fivepoint scale to indicate their agreement. We take the first as our focal question and relegate analysis of the remaining questions to the Online Appendix.

\footnotetext{
${ }^{13}$ We detail our search, including surveys consulted and the wording and years of relevant questions, in Online Appendix B.

${ }^{14}$ See "Trends in Pension Eligibility Ages and Life Expectancy, 1950-2050," OECD publication.
} 


\subsubsection{German Data}

The German General Social Survey has been fielded roughly every other year since $1980 .{ }^{15}$ Unfortunately, the German GSS redistributive questions are both less comparable to the American GSS and asked less frequently than those in the BSA. The German GSS asks individuals to place themselves on a four-point scale based on agreement with: "The state must ensure that people can live on a decent income, even in illness, hardship, unemployment and old age." In another question, again using a four-point scale, individuals are asked to react to the statement "Income should not be based solely on individual achievement. Instead, everybody should have what they and their family need for a decent life" as well as "Only when differences in income and in social standing are large enough, is there an incentive for individual achievement." Given that the first statement involves the role of government, we take it as the one closest to the GSS "reduce income differences" question and therefore define it as our focal question, again relegating analyses using the remaining questions to the Online Appendix.

\subsubsection{Swedish Data}

The Swedish National Election Studies (SNES) Program was established in 1954 to study public opinion and voting behavior. Since 1988, the SNES has asked respondents to indicate their agreement (on a five point scale) with the statement: "Here are a number of proposals that have appeared in the political debate. What is your opinion about...the proposal to: Reduce income differences in society."

\subsubsection{International Evidence}

We replicate our elderly graphs using the international data in Appendix Figures 1, 2 and 3. For each country, it is clear that the elderly are not differentially moving away from redistribution, relative to the rest of the population. Additionally, we recognize that the German reunification introduced composition issues, but in Online Appendix Figure A.6 we find that the same general pattern holds when we restrict the sample to those living in the territory of old Federal Republic (West Germany).

In Figure 5 we attempt to compare these trends in a more harmonized way across our five datasets (our three datasets from European countries plus the ANES and GSS). We first

\footnotetext{
${ }^{15}$ According to the German Social Survey (ALLBUS) Program, prior to German reunification the sample of respondents was drawn from West Germany and West Berlin.
} 
standardize each of the questions by dividing by its standard deviation. We next regress, separately for each dataset, these standardized variables on an elderly dummy, year fixed effects and an elderly-specific trend (i.e., the col. 1 specification in Table 1). We then generate lines defined by the elderly dummy and the elderly trend, so that for each year we give the predicted difference in support for redistribution among the elderly relative to others, separately by dataset. We only generate this line over the sample period of each dataset.

Figure 5 highlights how differently the elderly have evolved on redistribution in the US relative to similar, wealthy countries. Each of the other countries show, if anything, that the elderly are growing more supportive of redistribution relative to others (significantly so in Germany and Sweden). For each of the U.S. datasets, the 95\% confidence intervals do not include any of the point-estimates generated by the European data.

Past work has found that relative to other developed countries, American social spending is more tilted toward the elderly (see, e.g., Lynch, 2001 and Tepe and Vanhuysse, 2010). In fact, these calculations typically exclude health spending, suggesting elderly-bias is understated in the US, as until very recently the elderly were one of the few groups guaranteed government-subsidized health care in the US. The disproportionate gains to the American elderly in terms of social spending over the past several decades may make them wary of extending redistributive programs. The next section explores this idea in the context of health insurance.

\subsection{Do views on government health insurance explain the elderly trend?}

As the previous section noted, the elderly in the US have many important similarities with their counterparts in other OECD countries. However, the U.S. social insurance system exhibits a key difference: Those 65 and over are the only immutable group universally guaranteed government provided health insurance (i.e., not means-tested or dependent on documented disability status), whereas in other OECD countries that benefit does not depend on age.

Extending that protection to the rest of the population has been a key policy goal for the American left for decades. Indeed, the last two Democratic presidents made passing universal health insurance their first major policy goal upon taking office, though only the current president, Barack Obama, can be said to have succeeded in that realm. In fact, views about whether "it is the government's responsibility to pay for doctor's and hospital bills" 
predict both Democratic party identification and self-identification as "liberal" as strongly as do views on redistribution. ${ }^{16}$

In this section we explore the idea that seniors, a group unique in having guaranteed health insurance, may increasingly feel that expansions of redistributive programs could come at their expense. This is a view supported somewhat by the academic literature, most recently McInerney et al. (2015), who find a reduction in spending on Medicare patients following state Medicaid expansions. However, like prior work on the topic, the authors find no evidence of reductions in health access or outcomes. Well placed or not, as we mentioned previously, past work has shown that the fear of Medicare cuts triggers seniors' political activism (Campbell (2003)). ${ }^{17}$

In this section we ask two questions: have seniors become increasingly opposed to government health insurance over our sample period and, if so, can this increased opposition explain their general decline in redistributive sentiment?

\subsubsection{Seniors' views on government health insurance}

Both the GSS and the ANES ask respondents about their views on government health insurance. We focus on the GSS as this question is asked more often, though demonstrate robustness with the ANES. Figure 6(a) shows the evolution over our sample period of views on whether the government has the responsibility to pay for medical bills, separately for seniors and other adults. Seniors show a significant decline in their support on this question, moving (in the Republican direction) about one-third the partisan gap. In contrast, other adults have become significantly more favorable toward the idea that government bears some responsibility for covering medical costs.

One might ask how, by the end of our sample period, seniors can be less supportive of the idea that government cover medical bills given that they, uniquely, are categorically entitled to this coverage. Mettler (2010) analyzes a 2008 survey, finding that $40 \%$ of Medicare recipients answer that "they do not use a government social program," suggesting a lower bound of $40 \%$ of Medicare recipients who do not consider Medicare a government social program. Most Medicare recipients pay a premium (that covers $25 \%$ of Part B costs), perhaps leading them to think they cover the actuarial cost of the program. Finally, an increasing share of Medicare beneficiaries join private Medicare Advantage health plans (fully financed

\footnotetext{
${ }^{16}$ Authors' calculations using the GSS.

${ }^{17}$ This idea was certainly emphasized by media outlets that broadcasted video of irate seniors with "Get your hands off my Medicare" signs at town hall meetings during the ACA debates.
} 
by capitation payments paid by the federal government), perhaps further weakening the program's association with government.

\subsubsection{Views on government health insurance and redistribution}

In Table 4, we explore whether respondents' views on government's role in covering medical bills explains the divergent trends of the elderly and African-Americans on redistribution. The first two columns of the table focus on the elderly results, with col. (1) replicating the baseline results with no additional controls, but including only the subsample that answers the government health insurance question. Col. (2) adds the control for views on government covering medical bills. Not surprisingly, views on health insurance strongly predict views on redistribution: moving one unit on this 1-5 question (so, from support to strongly support the idea that government should cover medical bills) increases support for redistribution by 0.50 points (or $40 \%$ of the partisan gap on redistribution).

More relevant for our analysis, controlling for this variable has a meaningful effect on the differential elderly trend over redistributive preferences. The coefficient is reduced by $40 \%$, though remains significant at the ten percent level and given the size of the standard errors, statistically indistinguishable from the original coefficient. This result is robust to controlling more flexibly for view on health insurance (allowing it to enter as a fixed effect for each level of support, instead of continuously, and interacting it with the elderly indicator). Results are available upon request.

Given how many potential stories we have tested in the GSS and found had little explanatory power, we worry that random chance might suggest that one story might show statistical significance even if it had no true explanatory power. To somewhat assuage these concerns, we replicate these patterns of results in the ANES. Most years since the 1970s, the ANES has fielded the following question: "Some people feel there should be a government insurance plan which would cover all medical and hospital expenses for everyone... Others feel that medical expenses should be paid by individuals, and through private insurance plans. Where do you place yourself on this scale?" We flip the variable so that it is increasing in support for government health insurance.

Figure 6(b) shows how elderly versus other adult respondents have evolved on this question. As with the GSS, the elderly started the sample period more supportive than other adults, but have substantially moved against the idea, so that by the end of the sample period they are well below the rest of adults in their support. As in the GSS, non-elderly adults have 
become more supportive of the idea of government insurance. When we replicate the Table 4 analysis using ANES data, we find that attitudes toward government insurance explain a larger share - nearly 60\% — of the differential elderly trend on redistributive preferences, rendering the coefficient of interest insignificant. Results are available upon request.

A final point to discuss about both the GSS and ANES regression results is that the effect of controlling for views on health insurance is more muted for the regressions comparing black and non-black redistributive trends. Blacks have slightly reduced their support for government insurance relative to others, but the differential trend is small and insignificant, supporting the idea that growing reservations about government health insurance is a trend unique to the elderly during this period.

\section{Blacks and fairness}

There is a large literature linking redistributive preferences to perceptions of fairness (see for example Alesina and Angeletos, 2005 and Durante et al., 2013). Those who believe the distribution of income is fair are less likely to support government redistribution. Blacks fit this model. Although we have shown their support is declining, the level of black support for income redistribution remains higher than that of whites. Blacks are also on average less likely than whites to say that economic rewards are fairly earned, a belief that is not surprising given a legacy of slavery and segregation.

There are reasons to believe, however, that black views about fairness may be changing. Although the black-white earnings gap is remarkably persistent, ${ }^{18}$ Stevenson and Wolfers (2013) document in the GSS a decline in the black-white happiness gap, a finding the authors attribute to social gains in the arena of civil rights. In this section we ask two questions. First, do blacks believe that economic rewards are becoming more fairly distributed And if so, does this changing view "explain," in a regression sense, their decreased support for redistribution?

We measure respondents' sense of fairness using three questions across two surveys. Our first question, drawn from the GSS, asks "Some people say that people get ahead by their own hard work; others say that lucky breaks or help from other people are more important. Which do you think is most important?" Valid answers are 1) hard work 2) equally important

\footnotetext{
${ }^{18}$ See Altonji and Blank (1999) on the stalling of the black-white wage convergence. In the most recent decade, the black-white gap has in fact grown (see www.census.gov/prod/2013pubs/p60245.pdf).
} 
and 3) luck. We refer to this as our "luck" question. In Figure 7 we graph responses by race. Two things are notable. First, as expected blacks are on average more likely than whites to say luck is more important than hard work. But second, the back-white gap has closed significantly — by a full partisan unit — over our sample period.

We next complement the fairness measure by examining views on aid targeted specifically to blacks. Is an increasing sense of fairness coupled with a view that race specific aid is less desirable? Both the GSS and the ANES have questions on this issue. The GSS asks, "Some people think that (Blacks/Negroes/African-Americans) have been discriminated against for so long that the government has a special obligation to help improve their living standards. Others believe that the government should not be giving special treatment to (Blacks/Negroes/African-Americans). Where would you place yourself on this scale, or haven't you made up your mind on this?" Respondents are offered a scale from government should help blacks (1) through no special treatment (5). ANES asks, "Some people feel that the government in Washington should make every possible effort to improve the social and economic position of blacks and other minority groups. (Suppose these people are at one end of a scale, at point 1. Others feel that the government should not make any special effort to help blacks because they should help themselves. Suppose these people are at the other end, at point 7. And, of course, some other people have opinions somewhere in between, at points $2,3,4,5$ or 6 . Where would you place yourself on this scale, or haven't you thought much about it?" We reorient both measures so that they are increasing in support for race-based aid. We refer to these questions as our GSS and ANES "black aid" questions.

As shown in Figure 8 responses to the ANES and GSS questions show similar patterns. In both cases, blacks are, unsurprisingly, more likely than whites to support government aid targeted to blacks. But what is remarkable is that the views by race are converging, as over time blacks have become less supportive of special treatment for blacks by the government. And like the movement on the luck measure, the trend for blacks on government aid to blacks is quite steep. The scaled drop in support is over three-quarters of full party distance in the GSS and more than 1.5 times that distance in the ANES. Blacks view the economic system as becoming increasingly fair and are decreasingly supportive of government targeted aid based on race.

Does this changing sense of fairness "explain" blacks' decreased support for redistribution? We examine this question in Table 5. In columns 1 and 2 ( 5 and 6 for the patterns by age) we limit focus to the sample for which we have non-missing responses to the "luck" ques- 
tion. We find like previous literature that a belief that luck determines outcomes positively predicts support for redistribution. Nonetheless, controlling for this belief only accounts for two percent of the black-white redistribution trend gap. (The luck control explains none of the elderly pattern.) In the remaining columns of the table we restrict attention to the sample for which we have non-missing responses to the "black aid" question. Support for "black aid" predicts support for redistribution. And controlling for "black aid" explains $45 \%$ of the decline in black support for redistribution. But this "explanation" is not unique to blacks. The control explains over $20 \%$ of the decline in elderly support.

Thus although we have "explained" in a regression sense nearly half of the black trend in redistribution, we recognize that this "explanation" creates new puzzles: Why, in the face of stalled economic catch up, are blacks decreasingly supportive of racially targeted aid?

\section{Conclusion}

Americans have had a puzzling reaction to rising economic inequality. Across a 30-40 year period of increasing inequality, survey respondents have failed to increase their support for redistribution. While we do not claim to have resolved the mystery, we have tried to offer a number of clues.

First, we demonstrated that the overall flat trend in support for redistribution, masks considerable and surprising heterogeneity. Blacks and the elderly, two groups who are relatively more reliant on government assistance, have significantly decreased support for redistribution over the sample period relative to other Americans.

Second, we probed various hypotheses as to why redistributive support has trended downward amongst these populations. We do not find evidence consistent with more common models of redistribution. Measures of economic and more general well-being fail to explain (in a regression sense) either trend, with the exception of the education control (perhaps a proxy for permanent income in a retired population) which explains about a $30 \%$ of the elderly trend. Nor do we find evidence that these trends reflect a wider movement towards conservatism amongst these groups. In fact, blacks have identified increasingly as Democrats over the period.

Third, we moved beyond the more basic models to generate and test hypotheses unique to each group. In the case of the elderly, we can rule out that the trend is driven by something particular to the modern aging process, as we do not see a similar pattern in OECD countries with comparable data. Instead, we hypothesize that the trend derives from a uniquely Amer- 
ican concern. The elderly in the US are the only immutable group entitled to government health insurance. Thus we ask in this period in which universal health care has moved in and out of policy discussions, whether seniors, perhaps concerned about the crowd out of funding for their own care, have grown increasingly unsupportive of extending guaranteed government health care. We find not only a trend of decreasing support for universal care, but that this variable "explains" $40 \%$ of the elderly's decreased support for redistribution.

For blacks, we offer not as much of a hypothesis, but the identification of a concurrent trend. We find that blacks, while more likely than whites to support racially-targeted government aid, are converging toward the opinion of whites. (Concurrently and perhaps relatedly, blacks are increasingly likely to say that economic outcomes can be attributed to hard work over luck.) We find this decrease in support for race-based aid "explains" nearly $45 \%$ of blacks' decreased support for redistribution, a finding that deepens the puzzle: Why is support for race-targeted aid decreasing during a period in which the black-white wage gap has stagnated?

Finally, while we have framed the question for the most part as "why have blacks moved against redistribution" an equally legitimate framing is "why have whites not moved against redistribution." A possibility is that whites turned against redistribution during the Civil Rights movement, when blacks became more able to enjoy the benefits of full citizenship and government safety-net benefits. To the extent that whites' reaction to this one-time shock was either an over-reaction (and thus led to some regression to the mean) or a drop in support to an extreme negative value (and thus floor effects prevent a further negative trend) then mechanically whites may be unable to move further against redistribution. Unfortunately, it is difficult to piece together a consistent time series on redistributive preferences from both before and after the Civil Rights movement. However Kuziemko and Washington (2015) show that among whites declines in Democratic party identification (a potential proxy for redistributive preferences) after 1963 are highly correlated with conservative racial views, especially in the South. ${ }^{19}$

We present these ideas not as firm conclusions but as hopefully useful starting points for researchers who may confirm or challenge these ideas as they seek to explain the trend of

\footnotetext{
${ }^{19}$ We thank our discussant Peter Enns for this fascinating hypothesis. It picks up on an idea in Lee and Roemer (2006) that before the Democratic Party's 1960s Civil Rights initiatives, "it was possible, in the South, to vote both 'redistributive' and 'racist' simultaneously. Afterwards it was not - and the Southern white vote gradually moved from the Democratic to Republican parties. Thus, ironically, the Civil Rights Movement may have decreased the degree of redistribution in the United States."
} 
redistributive views in the United States during this period of rising inequality. 


\section{REFERENCES}

(). GESIS Leibniz Institute for the Social Sciences, German General Social Survey (ALLBUS) Cumulation 1980-2012 [computer file]. Cologne, Germany: GESIS Data Archive [distributor]. Accessed: September 2014.

(). Social and community planning research, British Social Attitudes Survey, 1983-2013 [computer file]. Colchester, Essex: UK Data archive [distributor]. Accessed: September 2014.

Alesina, A. and Angeletos, G.-M. (2005). Fairness and redistribution. American Economic Review, pp. 960-980.

Altonji, J. G. and Blank, R. M. (1999). Race and gender in the labor market. Handbook of labor economics, 3, 3143-3259.

Atkinson, A. B., Piketty, T. and Saez, E. (2011). Top incomes in the long run of history. Journal of Economic Literature, 49 (1), 3-71.

Autor, D. H. (2014). Skills, education, and the rise of earnings inequality among the other 99 percent. Science, 344 (6186), 843-851.

Beasley, R. K. and Joslyn, M. R. (2001). Cognitive dissonance and post-decision attitude change in six presidential elections. Political Psychology, 22 (3), 521-540.

Benabou, R. and OK, E. (2001). Social mobility and the demand for redistribution: The POUM hypothesis. Quarterly Journal of Economics, 116 (2), 447-487.

Campbell, A. L. (2003). Participatory reactions to policy threats: Senior citizens and the defense of social security and medicare. Political Behavior, 25 (1), 29-49.

Checchi, D., Ichino, A. and Rustichini, A. (1999). More equal but less mobile?: Education financing and intergenerational mobility in italy and in the us. Journal of public economics, 74 (3), 351-393.

Corneo, G. and Grüner, H. P. (2002). Individual preferences for political redistribution. Journal of public Economics, 83 (1), 83-107.

Durante, R., Putterman, L. and Van der Weele, J. J. (2013). Preferences for redistribution and perception of fairness: An experimental study. Forthcoming, Journal of the European Economic Association.

Festinger, L. (1957). A Theory of Cognitive Dissonance. Row, Peterson \& Co.

Gerber, A. S., Huber, G. A. and Washington, E. (2010). Party affiliation, partisanship, and political beliefs: A field experiment. American Political Science Review, 104 (04), $720-744$.

Hirschman, A. O. and Rothschild, M. (1973). The changing tolerance for income inequality in the course of economic development. The Quarterly Journal of Economics, pp. $544-566$. 
Kelly, N. and Enns, P. (2010). Inequality and the dynamics of public opinion: The selfreinforcing link between economic inequality and mass preferences. American Journal of Political Science.

Kenworthy, L. and McCall, L. (2008). Inequality, public opinion and redistribution. Socio-Economic Review, 6 (1), 35.

Kuziemko, I., Norton, M. I., Saez, E. and Stantcheva, S. (2013). How Elastic Are Preferences for Redistribution? Evidence from Randomized Survey Experiments. Working Paper 18865, National Bureau of Economic Research.

- and Washington, E. (2015). Why did the Democrats lose the South? Bringing new data to an old Debate, mimeo, Princeton.

Layman, G. C. (1997). Religion and political behavior in the united states: The impact of beliefs, affiliations, and commitment from 1980 to 1994. Public Opinion Quarterly, pp. 288-316.

Lee, W. and Roemer, J. E. (2006). Racism and redistribution in the United States: A solution to the problem of American exceptionalism. Journal of Public Economics, 90 (6), $1027-1052$.

Lynch, J. (2001). The age-orientation of social policy regimes in oecd countries. Journal of Social Policy, 30 (03), 411-436.

McInerney, M., Mellor, J. and Sabik, L. (2015). The effects of state medicaid expansions for working-age adults on senior medicare beneficiaries' healthcare spending, unpublished working paper.

Meltzer, A. and Richard, S. (1981). A rational theory of the size of government. The Journal of Political Economy, 89 (5), 914-927.

Mettler, S. (2010). Reconstituting the submerged state: The challenges of social policy reform in the obama era. Perspectives on Politics, 8 (03), 803-824.

Mullainathan, S. and Washington, E. (2009). Sticking with your vote: Cognitive dissonance and political attitudes. American Economic Journal: Applied Economics, 1 (1), $86-111$.

Oscarsson, H. (). Swedish national election study, 1956-2006 [computer file]. gothenburg, sweden: Swedish national data service [distributor]. Accessed: December 2014.

Piketty, T. and SAez, E. (2003). Income inequality in the united states, 1913-1998. The Quarterly Journal of Economics, 118 (1), 1-41.

Ravallion, M. and Lokshin, M. (2000). Who wants to redistribute?: The tunnel effect in 1990s russia. Journal of public Economics, 76 (1), 87-104.

Stevenson, B. and Wolfers, J. (2013). Subjective and objective indicators of racial progress. Tech. rep., National Bureau of Economic Research. 
Tepe, M. and Vanhuysse, P. (2010). Elderly bias, new social risks and social spending: change and timing in eight programmes across four worlds of welfare, 1980-2003. Journal of European Social Policy, 20 (3), 217-234. 
Figure 1: Income share of the top one percent

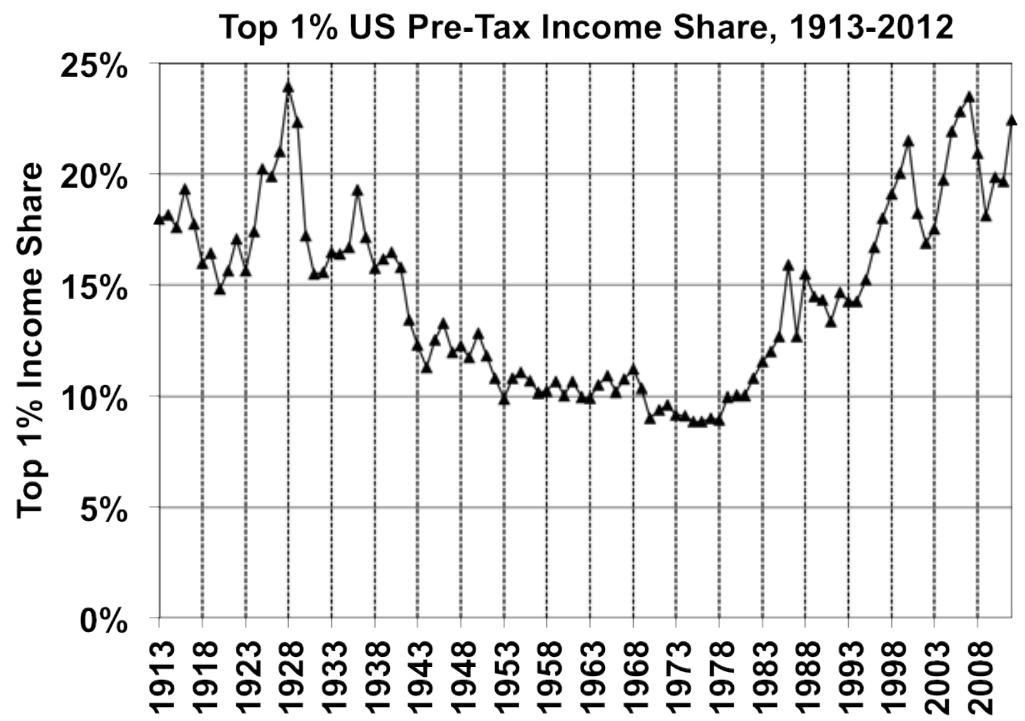

Source: Piketty and Saez, 2003 updated to 2011. Series based on pre-tax cash market income including realized capital gains and excluding government transfers.

Notes: Taken from http://eml.berkeley.edu/ saez/TabFig2012prel.xls 
Figure 2: Trends in redistributive support

(a) Gov't sd. reduce inc. differences (1-7)

(b) Gov't sd. help poor (1-5)
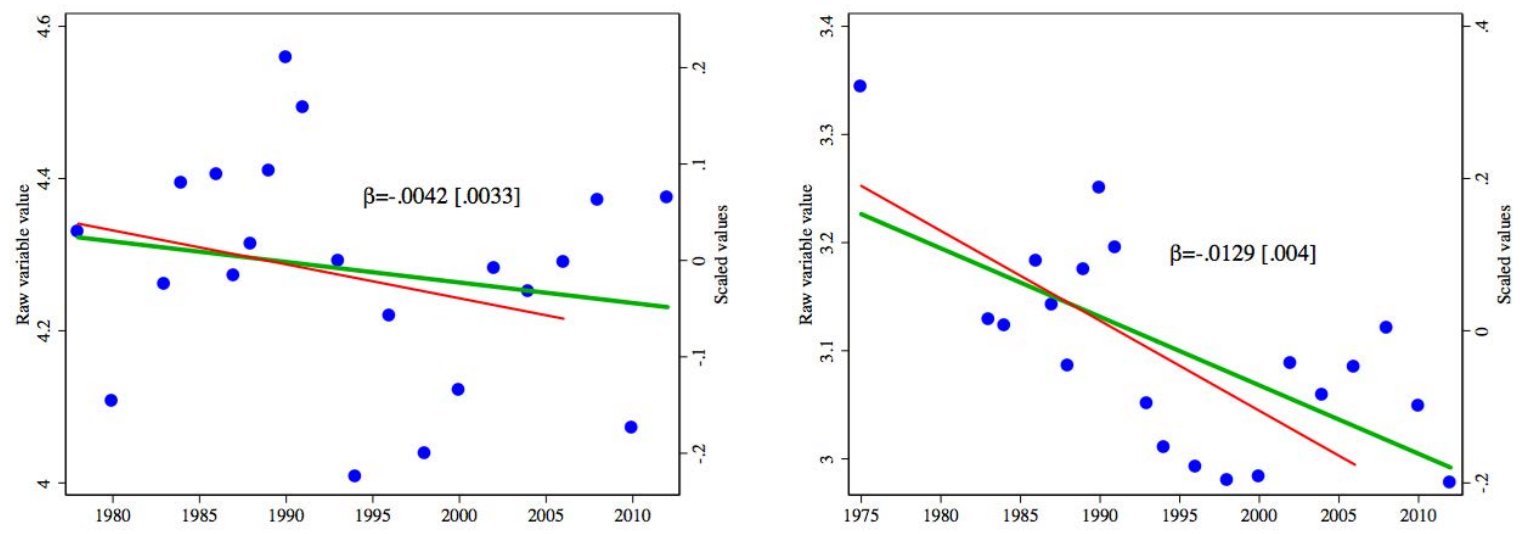

(c) Gov't sd. do more (1-5)

(d) Gov't sd. ensure work, st. living (1-7)
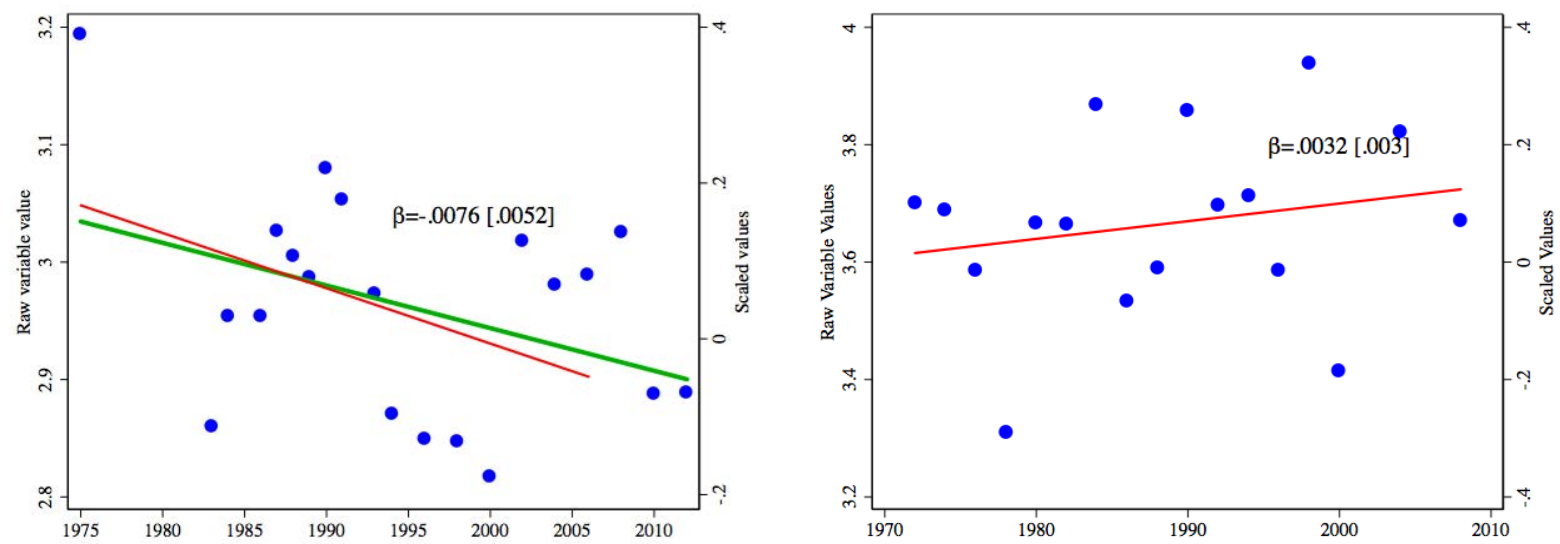

Notes: Figures depict measures of redistributive preferences: a) The eqwlth variable from the GSS which since 1978 asks whether the government should reduce income difference; b) The helppoor variable (GSS) which since 1975 asks whether the government should improve the standard of living of the poor; c) The helpnot variable (GSS) which since 1975 asks whether the government is trying to do too many things and d) The VCF0809 variable from the ANES, 1972-2008, which asks whether the government should ensure that each person has a job and a good standard of living. The shorter lines (graphs a-c) depict trends through 2006 only; the longer line through 2012. Variables are reoriented (if necessary) so that scales are increasing in support for redistribution. The left-hand axes show "native units" of each variable. The right-hand axes plot a linear transformation of each variable in which it is demeaned and divided by the partisan gap, where partisan gap is the difference between the average Democrat and the average Republican answering that question. Therefore, 0 on the right-hand axes represents the view of the average respondent during the sample period, and a one-unit positive change is equal to moving (in the Democratic direction) the distance between the average Democrat and the average Republican. Slopes and standard errors of shorter lines indicated in standardized units. 
Figure 3: Trends in redistributive support, by age and race

(a) Gov't sd. reduce income diffs. (GSS)

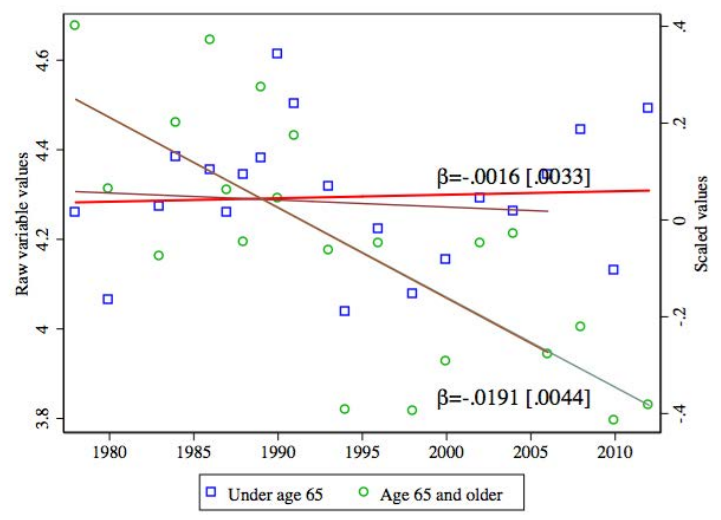

(c) Gov't sd. reduce income diffs. (GSS)

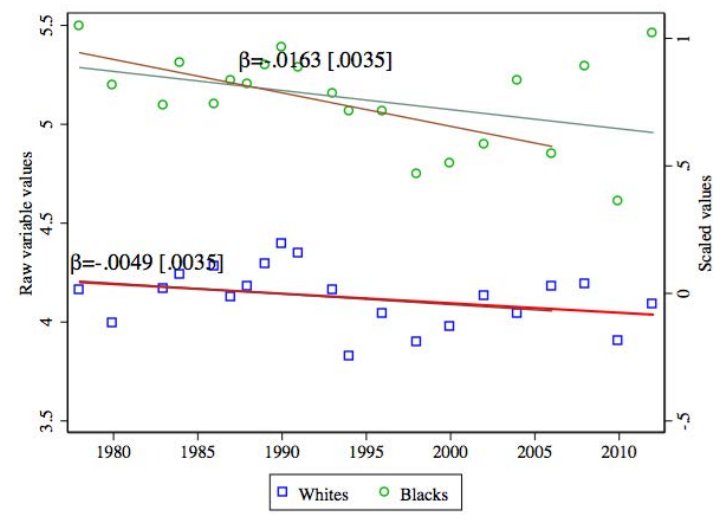

(b) Gov't sd. ensure work, st. living (ANES)

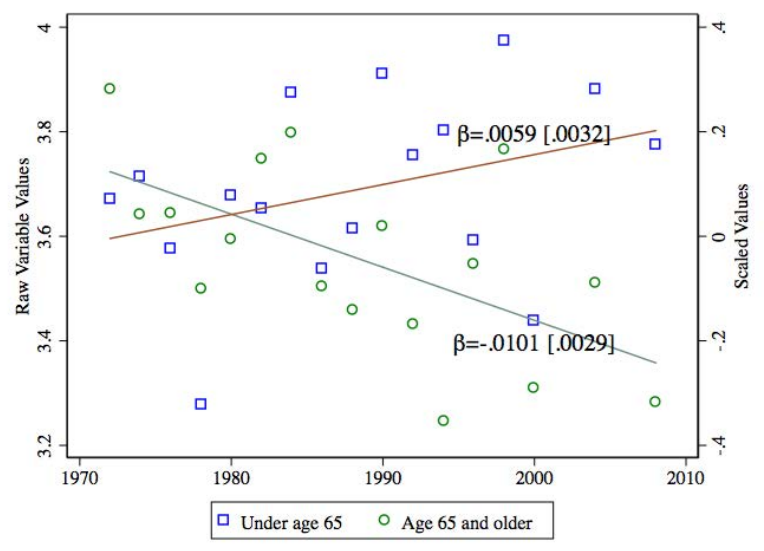

(d) Gov't sd. ensure work, st. living (ANES)

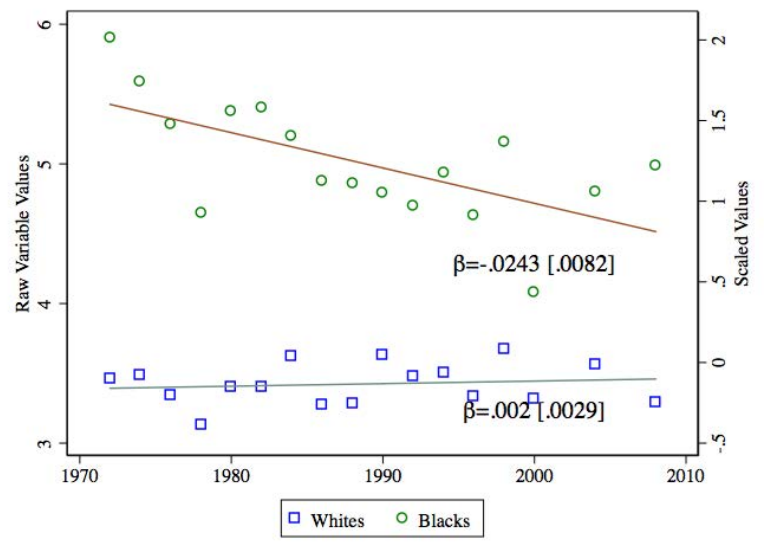

Notes: Figures depict by age and race, measures of redistributive preferences: a) and c) The eqwlth variable from the GSS which since 1978 asks whether the government should reduce income difference; and b and d) The VCF0809 variable(1972-2008) from the ANES which asks whether the government should ensure that each person has a job and a good standard of living. The shorter lines (graphs a and c) depict trends through 2006 only; the longer lines through 2012. Variables are reoriented (if necessary) so that scales are increasing in support for redistribution. The left-hand axes show "native units" of each variable. The right-hand axes plot a linear transformation each variable in which it is demeaned and divided by the partisan gap, where partisan gap is the difference between the average Democrat and the average Republican answering that question. Therefore, 0 on the right-hand axes represents the view of the average respondent during the sample period, and a one-unit positive change is equal to moving (in the Democratic direction) the distance between the average Democrat and the average Republican. Slopes and standard errors of shorter lines indicated in standardized units 
Figure 4: Trends in redistributive support, by gender

(a) Gov't sd. reduce income diffs. (GSS)

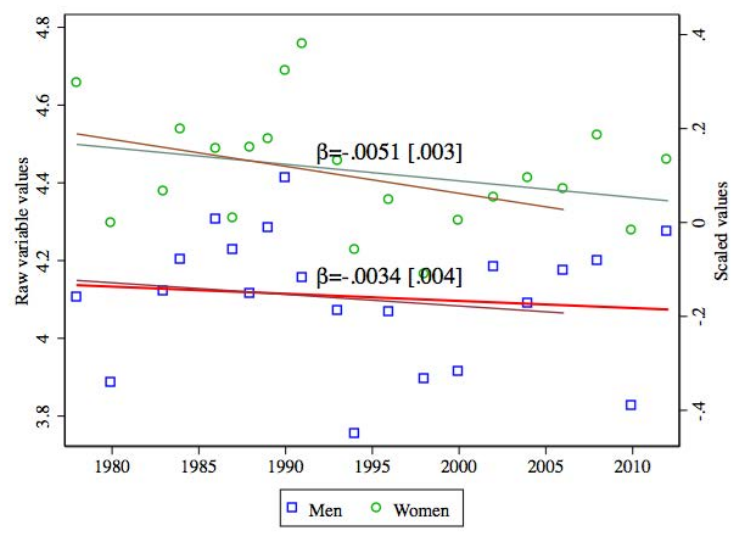

(b) Gov't sd. guarantee work, st. living (ANES)

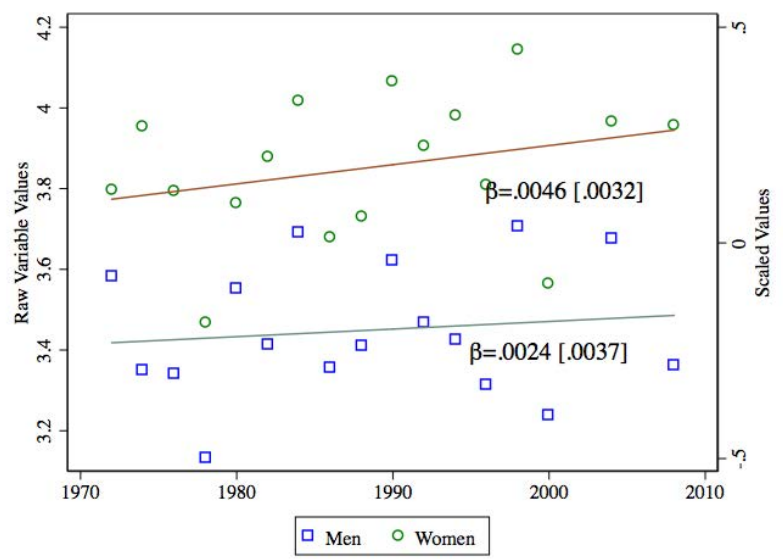

Notes: Figures depict, by gender, a) responses to the eqwlth variable from the GSS which since 1978 asks whether the government should reduce income difference and b) he VCF0809 variable(1972-2008) from the ANES which asks whether the government should ensure that each person has a job and a good standard of living. The shorter line (graph a) depicts trend through 2006 only; the longer line through 2012. Variables are reoriented so that scales are increasing in support for redistribution. The left-hand axes show "native units" of each variable. The right-hand axes plot a linear transformation each variable in which it is demeaned and divided by the partisan gap, where partisan gap is the difference between the average Democrat and the average Republican answering that question. Therefore, 0 on the right-hand axes represents the view of the average respondent during the sample period, and a one-unit positive change is equal to moving (in the Democratic direction) the distance between the average Democrat and the average Republican. Slopes and standard errors of shorter lines indicated in standardized units. 
Figure 5: Relative elderly trend on redistributive issues, by country

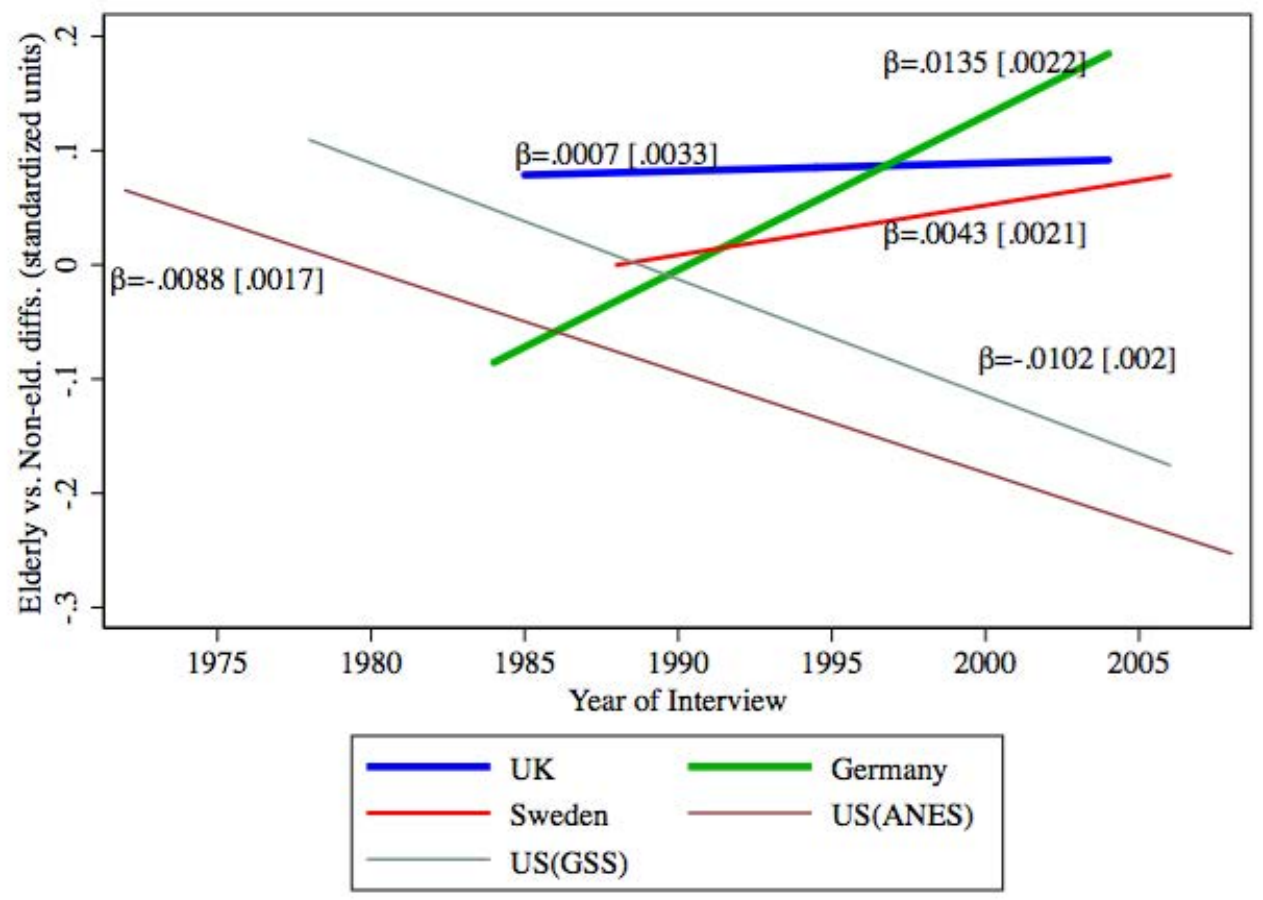

Notes: Figure depicts the difference in the standardized trends in redistributive support between the elderly and nonelderly (elderly minus non-elderly) as measured in each national survey: For the UK, whether the government should reduce income differences (incdiff variable in the British Social Attitudes Survey, 1985-2004); for Germany, whether the state should ensure people a decent income (V183 variable in the German General Social Survey, 1984-2004); for Sweden, whether the government should reduce income differences (v121, v130, v131, v142, v153 and v406 variables in the Swedish National Election Studies Program, 1988-2006); for the US (GSS), whether the government should reduce income differences (eqwlth variable, 1978-2006); for the US (ANES), whether the government should ensure that each person has a job and a good standard of living ( VCF0809 variable, 1972-2008). The dependent variable in each dataset is reoriented so that scales are increasing in support for redistribution and is divided by its standard deviation. Slopes and standard errors indicated in standardized units. 
Figure 6: Trends in support for government health insurance, by age

(a) Gov't sd. cover medical bills, GSS

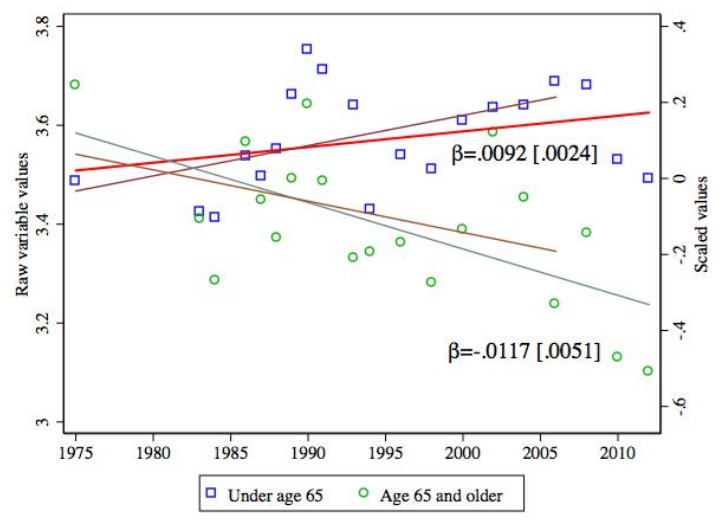

(b) Gov't sd. provide health ins. for all, ANES

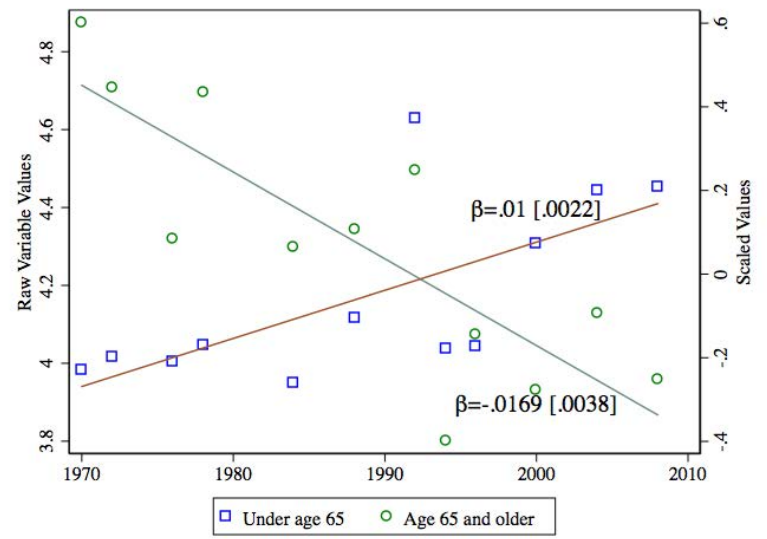

Notes: Figures depict responses to the help sick variable from the GSS which asks since 1974 whether the government has the responsibility to pay for medical bills and to the VCF0806 variable from the ANES, 1972-2008, which asks whether there should be government provided health insurance for all. The shorter line (graph a) depicts trends through 2006; the longer line through 2012. Variables are reoriented (if necessary) so that scales are increasing in support for public health care. The left-hand axes show "native units" of each variable. The right-hand axes plot a linear transformation of each variable in which it is demeaned and divided by the partisan gap, where partisan gap is the difference between the average Democrat and the average Republican answering that question. Therefore, 0 on the right-hand axes represents the view of the average respondent during the sample period, and a one-unit positive change is equal to moving (in the Democratic direction) the distance between the average Democrat and the average Republican. 
Figure 7: Luck and help key to success, by race (GSS)

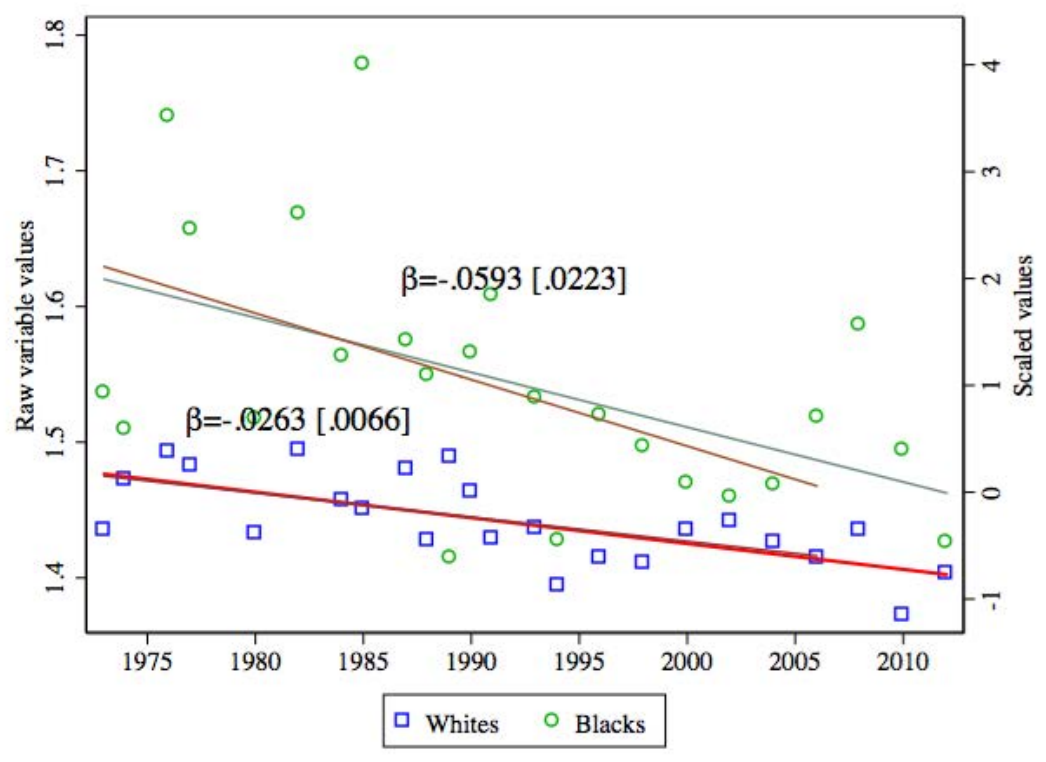

Notes: The graph uses the getahead variable from the GSS. The shorter line depicts the trend line through 2006 only; the longer line through 2012. The left-hand axis uses the "native units" of the GSS variable. The right-hand side plots a linear transformation of that variable: it is demeaned and divided by the partisan gap, where partisan gap is the difference between the average Democrat and the average Republican answering that question. Therefore, 0 on the right-hand axis represents the view of the average respondent during the sample period, and a one-unit positive change is equal to moving (in the Democratic direction) the distance between the average Democrat and the average Republican. 
Figure 8: Trends in support for government aid to blacks, by race

(a) Gov't sd. treat blacks specially, GSS

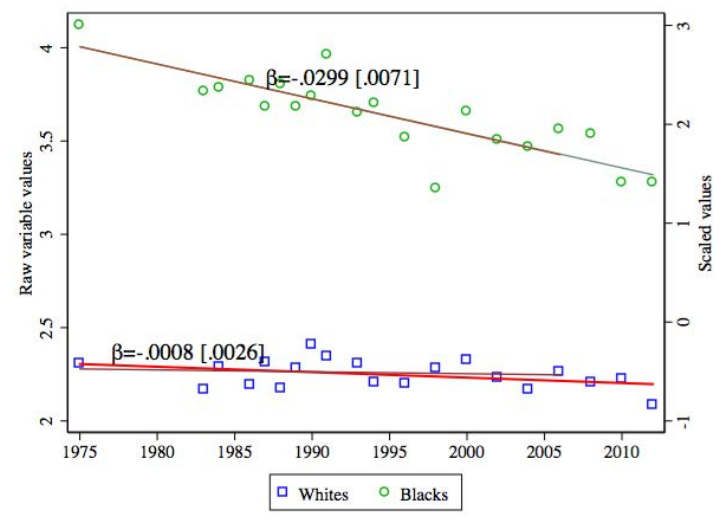

(b) Gov't sd. help blacks, ANES

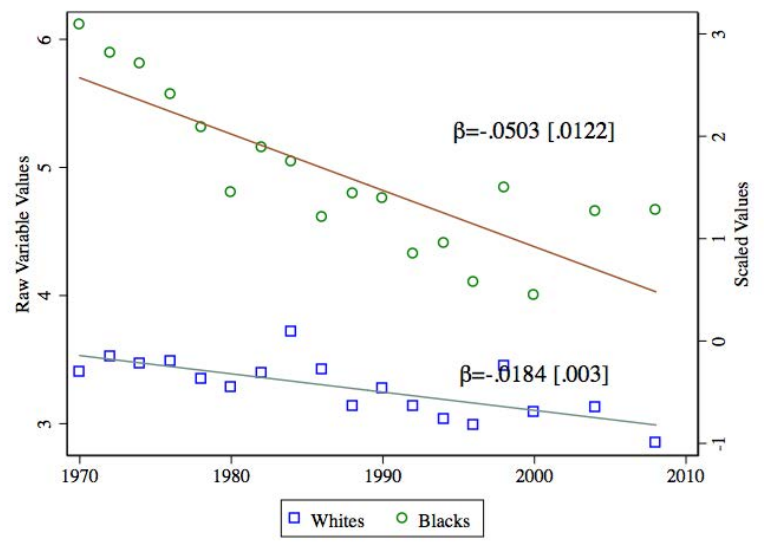

Notes: Figures depict responses to a) helpblk variable from the GSS and the b) the VCF0830 variable (ANES, 1972-2008). The shorter line (graph a) depicts through 2006 only; the longer line through 2012. Variables are reoriented (if necessary) so that scales are increasing in support for government aid to blacks. The left-hand axes show "native units" of each variable. The right-hand axes plot a linear transformation each variable in which it is demeaned and divided by the partisan gap, where partisan gap is the difference between the average Democrat and the average Republican answering that question. Therefore, 0 on the right-hand axes represents the view of the average respondent during the sample period, and a one-unit positive change is equal to moving (in the Democratic direction) the distance between the average Democrat and the average Republican. 
Table 1: Do income measures explain redistribution trends?

\begin{tabular}{|c|c|c|c|c|c|c|c|c|}
\hline & \multicolumn{8}{|c|}{ Reduce inc. diffs $(1-7)$} \\
\hline & (1) & (2) & (3) & (4) & (5) & (6) & (7) & (8) \\
\hline $\begin{array}{l}\text { Elderly x } \\
(\text { Year-1975)/100 }\end{array}$ & $\begin{array}{r}-1.995^{* * *} \\
{[0.401]}\end{array}$ & $\begin{array}{c}-1.924^{* * *} \\
{[0.388]}\end{array}$ & $\begin{array}{c}-1.403^{* * *} \\
{[0.381]}\end{array}$ & $\begin{array}{c}-1.720^{* * *} \\
{[0.394]}\end{array}$ & & & & \\
\hline $\begin{array}{l}\text { Black x } \\
(\text { Year-1975)/100 }\end{array}$ & & & & & $\begin{array}{r}-1.423^{* * *} \\
{[0.414]}\end{array}$ & $\begin{array}{c}-1.431^{* * *} \\
{[0.446]}\end{array}$ & $\begin{array}{c}-1.491^{* * *} \\
{[0.458]}\end{array}$ & $\begin{array}{c}-1.307^{* * *} \\
{[0.423]}\end{array}$ \\
\hline Mean, dept. var. & 4.251 & 4.252 & 4.251 & 4.251 & 4.252 & 4.254 & 4.252 & 4.252 \\
\hline Scaled effect (SD) & -1.023 & -0.987 & -0.720 & -0.882 & -0.730 & -0.734 & -0.765 & -0.670 \\
\hline Scaled effect (party) & -1.846 & -1.781 & -1.298 & -1.591 & -1.316 & -1.323 & -1.378 & -1.208 \\
\hline Income covar? & No & Yes & No & No & No & Yes & No & No \\
\hline Educ. covars? & No & No & Yes & No & No & No & Yes & No \\
\hline Relative covars? & No & No & No & Yes & No & No & No & Yes \\
\hline Share explained & & .0352112 & .2965051 & .1379481 & & -.0056065 & -0475128 & 3.0819684 \\
\hline Observations & 24388 & 24260 & 24388 & 24388 & 24463 & 24331 & 24463 & 24463 \\
\hline
\end{tabular}

All regressions run using GSS data and contain year fixed effects, cluster standard errors by year, and use provided survey weights. Col. (1) and (5) contain no additional controls except an elderly (black) indicator variable. Col. (2) and (6) contain the income measure (realinc) adjusted for household size (we follow the OECD and give each additional adult beyond the head a weight of 0.5 and each child a weight of 0.3 ) and inflation and coding missing values to zero, as well as an indicator variable for having a missing value for this variable. We lose some observations due to missing household-size inputs. Cols. (3) and (7) include fixed effects for highest degree attained ('missing' is its own category). Cols. (4) and (8) contain fixed effects for the five possible answers to where you see yourself in the U.S income distribution and the four possible answers for your self-assessed social class ('missing' is its own category). Section 2.1 provides additional detail. ${ }^{*} p<0.1,{ }^{* *} p<0.05,{ }^{* * *} p<0.01$ 
Table 2: Do broader measures of well-being explain redistribution trends?

\begin{tabular}{|c|c|c|c|c|c|c|c|c|c|c|c|c|}
\hline & \multicolumn{12}{|c|}{ Reduce inc. diffs (1-7) } \\
\hline & (1) & $(2)$ & $(3)$ & $(4)$ & $(5)$ & $(6)$ & $(7)$ & $(8)$ & (9) & $(10)$ & $(11)$ & $(12)$ \\
\hline $\begin{array}{l}\text { Elderly x } \\
(\text { Year-1975)/100 }\end{array}$ & $\begin{array}{c}-1.969^{* * *} \\
{[0.396]}\end{array}$ & $\begin{array}{c}-1.990^{* * *} \\
{[0.382]}\end{array}$ & $\begin{array}{c}-2.103^{* * *} \\
{[0.344]}\end{array}$ & $\begin{array}{c}-1.943^{* * *} \\
{[0.349]}\end{array}$ & $\begin{array}{l}-1.090 \\
{[1.239]}\end{array}$ & $\begin{array}{l}-1.129 \\
{[1.246]}\end{array}$ & & & & & & \\
\hline $\begin{array}{l}\text { Black x } \\
(\text { Year-1975)/100 }\end{array}$ & & & & & & & $\begin{array}{c}-1.410^{* * *} \\
{[0.438]}\end{array}$ & $\begin{array}{c}-1.270^{* *} \\
{[0.454]}\end{array}$ & $\begin{array}{c}-2.164^{* * *} \\
{[0.335]}\end{array}$ & $\begin{array}{c}-2.123^{* * *} \\
{[0.359]}\end{array}$ & $\begin{array}{c}-3.124^{*} \\
{[1.489]}\end{array}$ & $\begin{array}{c}-3.180^{*} \\
{[1.460]}\end{array}$ \\
\hline Happiness (1-3) & & $\begin{array}{c}-0.366^{* * *} \\
{[0.0196]}\end{array}$ & & & & & & $\begin{array}{c}-0.320^{* * *} \\
{[0.0205]}\end{array}$ & & & & \\
\hline Health (1-4) & & & & $\begin{array}{c}-0.295^{* * *} \\
{[0.0211]}\end{array}$ & & & & & & $\begin{array}{c}-0.253^{* * *} \\
{[0.0191]}\end{array}$ & & \\
\hline Kids will do worse & & & & & & $\begin{array}{l}-0.0476 \\
{[0.0247]}\end{array}$ & & & & & & $\begin{array}{l}-0.0207 \\
{[0.0238]}\end{array}$ \\
\hline $\begin{array}{l}\text { Doing worse than } \\
\text { parents }\end{array}$ & & & & & & $\begin{array}{c}0.0851^{* * *} \\
{[0.0153]}\end{array}$ & & & & & & $\begin{array}{c}0.0918^{* * *} \\
{[0.0151]}\end{array}$ \\
\hline Mean, dept. var. & 4.252 & 4.252 & 4.212 & 4.212 & 4.159 & 4.159 & 4.254 & 4.254 & 4.214 & 4.214 & 4.160 & 4.160 \\
\hline Scaled effect (SD) & -1.011 & -1.022 & -1.078 & -0.996 & -0.562 & -0.582 & -0.724 & -0.652 & -1.109 & -1.088 & -1.609 & -1.638 \\
\hline Scaled effect (party) & -1.822 & -1.841 & -1.922 & -1.776 & -0.901 & -0.933 & -1.304 & -1.174 & -1.976 & -1.938 & -2.584 & -2.631 \\
\hline Share explained & & -.0102991 & & .0763383 & & -.0357122 & & .0995062 & & .0190701 & & -.0179786 \\
\hline Observations & 24159 & 24159 & 14458 & 14458 & 9077 & 9077 & 24227 & 24227 & 14499 & 14499 & 9096 & 9096 \\
\hline
\end{tabular}

All regressions run using GSS and contain year fixed effects, cluster standard errors by year, and use provided survey weights. Odd columns contain no additional controls except an elderly (black) indicator variable. ${ }^{*} p<0.1,{ }^{* *} p<0.05,{ }^{* * *} p<0.01$ 
Table 3: Does general conservatism explain redistribution trends?

\begin{tabular}{|c|c|c|c|c|c|c|c|c|}
\hline & \multicolumn{8}{|c|}{ Reduce income differences (1-7) } \\
\hline & (1) & $(2)$ & $(3)$ & (4) & $(5)$ & $(6)$ & $(7)$ & $(8)$ \\
\hline $\begin{array}{l}\text { Elderly x } \\
(\text { Year-1975)/100 }\end{array}$ & $\begin{array}{c}-2.071^{* * *} \\
{[0.393]}\end{array}$ & $\begin{array}{c}-2.181^{* * *} \\
{[0.427]}\end{array}$ & $\begin{array}{c}-1.851^{* * *} \\
{[0.354]}\end{array}$ & $\begin{array}{c}-2.034^{* * *} \\
{[0.398]}\end{array}$ & & & & \\
\hline $\begin{array}{l}\text { Black x } \\
(\text { Year-1975)/100 }\end{array}$ & & & & & $\begin{array}{c}-1.500^{* * *} \\
{[0.453]}\end{array}$ & $\begin{array}{c}-1.720^{* * *} \\
{[0.434]}\end{array}$ & $\begin{array}{c}-1.462^{* * *} \\
{[0.498]}\end{array}$ & $\begin{array}{c}-1.391^{* * *} \\
{[0.451]}\end{array}$ \\
\hline Identify Republ. (1-7) & & $\begin{array}{l}-0.265^{* * *} \\
{[0.00904]}\end{array}$ & & & & $\begin{array}{l}-0.241^{* * *} \\
{[0.00995]}\end{array}$ & & \\
\hline Lib to cons $(1-7)$ & & & $\begin{array}{c}-0.306^{* * *} \\
{[0.0114]}\end{array}$ & & & & $\begin{array}{c}-0.290^{* * *} \\
{[0.0127]}\end{array}$ & \\
\hline $\begin{array}{l}\text { Relig. attendence } \\
(1-9)\end{array}$ & & & & $\begin{array}{c}-0.0264^{* * *} \\
{[0.00512]} \\
\end{array}$ & & & & $\begin{array}{r}-0.0372^{* * *} \\
{[0.00593]} \\
\end{array}$ \\
\hline Mean, dept. var. & 4.231 & 4.231 & 4.231 & 4.231 & 4.232 & 4.232 & 4.232 & 4.232 \\
\hline Scaled effect (SD) & -1.069 & -1.126 & -0.956 & -1.050 & -0.774 & -0.888 & -0.754 & -0.718 \\
\hline Scaled effect (party) & -1.936 & -2.039 & -1.731 & -1.902 & -1.402 & -1.608 & -1.366 & -1.301 \\
\hline Share explained & & -.0534258 & 8.1058472 & .0176777 & & -.1466506 & .0254986 & .0724976 \\
\hline Observations & 22119 & 22119 & 22119 & 22119 & 22172 & 22172 & 22172 & 22172 \\
\hline
\end{tabular}


Table 4: Do views on public health insurance explain redistributive trends?

\begin{tabular}{lcccc}
\hline & \multicolumn{4}{c}{ Reduce inc. diffs } \\
\cline { 2 - 5 } & $(1)$ & $(2)$ & $(3)$ & $(4)$ \\
\hline Elderly x & $-1.599^{* * *}$ & $-0.971^{*}$ & & \\
(Year-1975)/100 & {$[0.534]$} & {$[0.465]$} & & \\
Black x & & & $-1.279^{* *}$ & $-1.090^{*}$ \\
Year-1975)/100 & & {$[0.444]$} & {$[0.555]$} \\
Gov't medical care & & & & $0.479^{* * *}$ \\
& & $0.504^{* * *}$ & & {$[0.0221]$} \\
\hline Mean, dept. var. & 4.261 & 4.261 & 4.263 & 4.263 \\
Scaled effect (SD) & -0.821 & -0.499 & -0.657 & -0.559 \\
Scaled effect (party) & -1.436 & -0.872 & -1.148 & -0.978 \\
Share explained & - & .3924316 & - & .1482657 \\
Observations & 21710 & 21710 & 21773 & 21773 \\
\hline
\end{tabular}

All regressions run using GSS and contain year fixed effects, cluster standard errors by year, and use provided survey weights. ${ }^{*} p<0.1,{ }^{* *} p<0.05,{ }^{* * *} p<0.01$

Table 5: Do views on income merit and aid to blacks explain redistributive trends?

\begin{tabular}{lcccccccc}
\hline & \multicolumn{7}{c}{ Reduce inc. diffs } \\
\cline { 2 - 8 } & $(1)$ & $(2)$ & $(3)$ & $(4)$ & $(5)$ & $(6)$ & $(7)$ & $(8)$ \\
\hline Black x & $-1.626^{* *}$ & $-1.587^{* *}$ & $-1.228^{* *}$ & -0.677 & & & & \\
$($ Year-1975)/100 & {$[0.561]$} & {$[0.563]$} & {$[0.477]$} & {$[0.547]$} & & & & \\
Elderly x & & & & & $-2.186^{* * *}$ & $-2.207^{* * *}$ & $-1.492^{* *}$ & $-1.148^{*}$ \\
$($ Year-1975)/100 & & & & & {$[0.322]$} & {$[0.328]$} & {$[0.511]$} & {$[0.558]$} \\
Success mostly luck & & $0.0933^{* *}$ & & & & $0.104^{* * *}$ & & \\
& & {$[0.0323]$} & & & & {$[0.0325]$} & & \\
Gov't should help & & & & $0.315^{* * *}$ & & & & $0.360^{* * *}$ \\
blacks v. no spec. treat. & & & & {$[0.0260]$} & & & & {$[0.0228]$} \\
\hline Mean, dept. var. & 4.233 & 4.233 & 4.253 & 4.253 & 4.231 & 4.231 & 4.252 & 4.252 \\
Scaled effect (SD) & -0.833 & -0.813 & -0.630 & -0.347 & -1.120 & -1.132 & -0.765 & -0.589 \\
Scaled effect (party) & -1.482 & -1.446 & -1.104 & -0.609 & -1.995 & -2.015 & -1.343 & -1.034 \\
Share explained & - & .0243181 & - & .4489072 & - & -.0099724 & - & .2304056 \\
Observations & 12559 & 12559 & 21637 & 21637 & 12522 & 12522 & 21574 & 21574 \\
\hline Allyyyyyyyyyy
\end{tabular}

All regressions run using GSS and contain year fixed effects, cluster standard errors by year, and use provided survey weights. ${ }^{*} p<0.1,{ }^{* *} p<0.05,{ }^{* * *} p<0.01$ 


\section{Appendix}

Appendix Figure 1: Agreement that government should reduce income differences, elderly versus others, British Social Attitudes survey

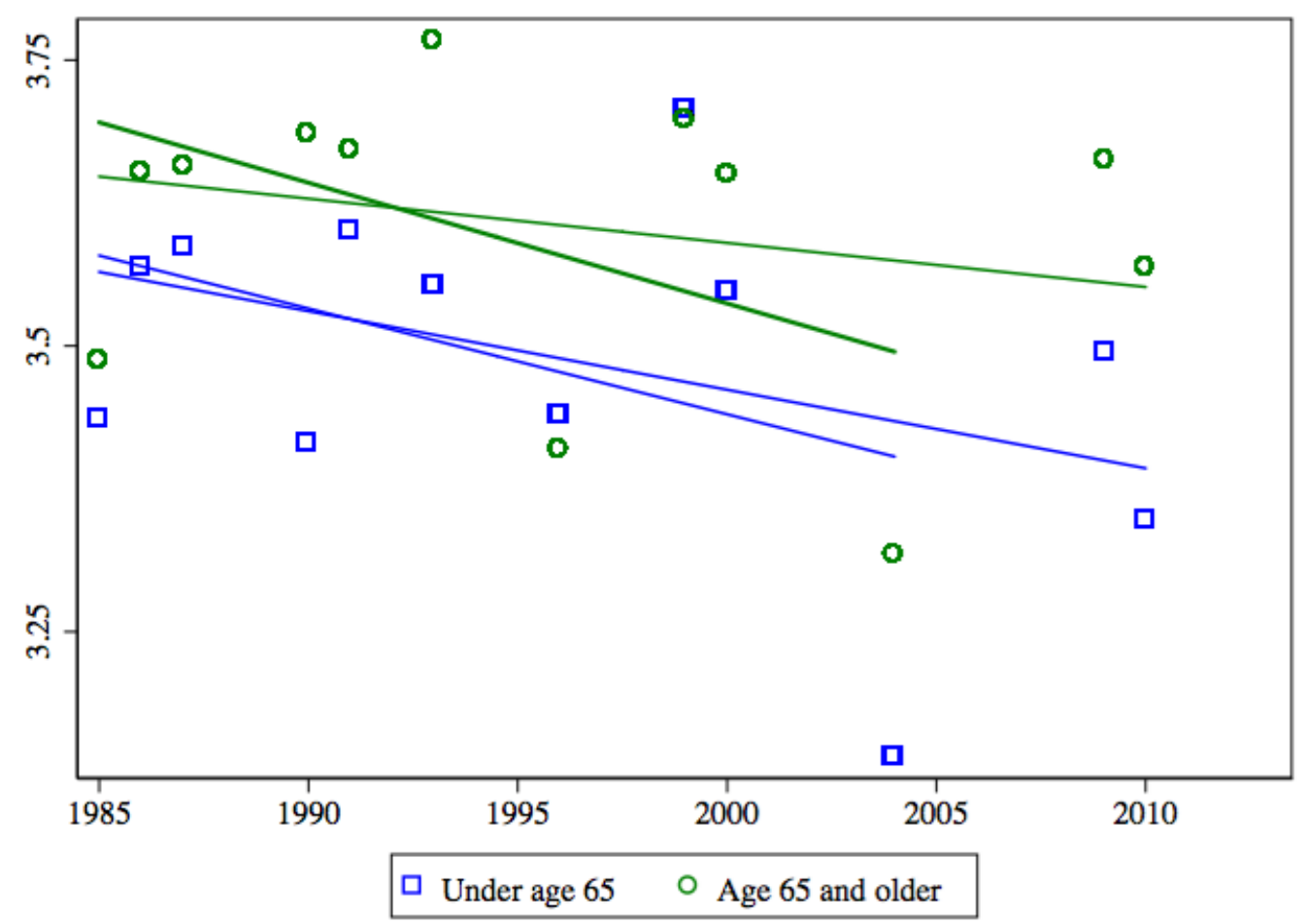

Notes: This figure depicts responses since 1985 in the British Social Attitudes (BSA) on whether the government should reduce income differences. The graph uses the incdiff variable from the BSA (though subtracts it from six so that it is increasing in support for government activism). The shorter line depicts the trend line from 1985 to 2004 only. 
Appendix Figure 2: Agreement that state should ensure decent income, elderly versus others, German General Social Survey (ALLBUS)

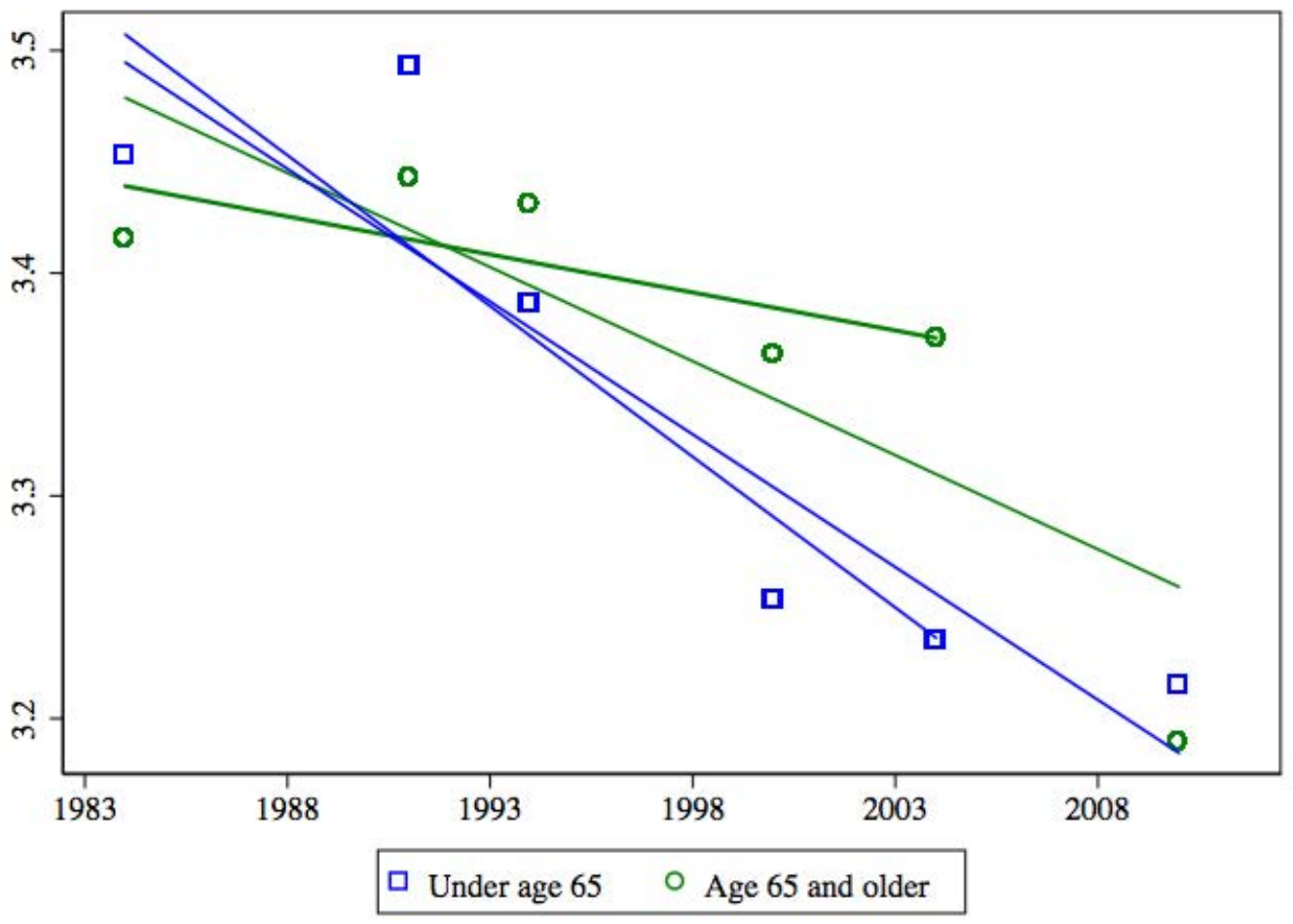

Notes: This figure depicts responses since 1984 in the German General Social Survey (ALLBUS) on whether the state should ensure people a decent income. The graph uses the V183 variable from the ALLBUS (though subtracts it from five so that it is increasing in support for government activism). The shorter line depicts the trend line from 1984 to 2004 only. 
Appendix Figure 3: Agreement with proposal to reduce income differences in society, elderly versus others, Swedish National Election Studies (SNES) Program

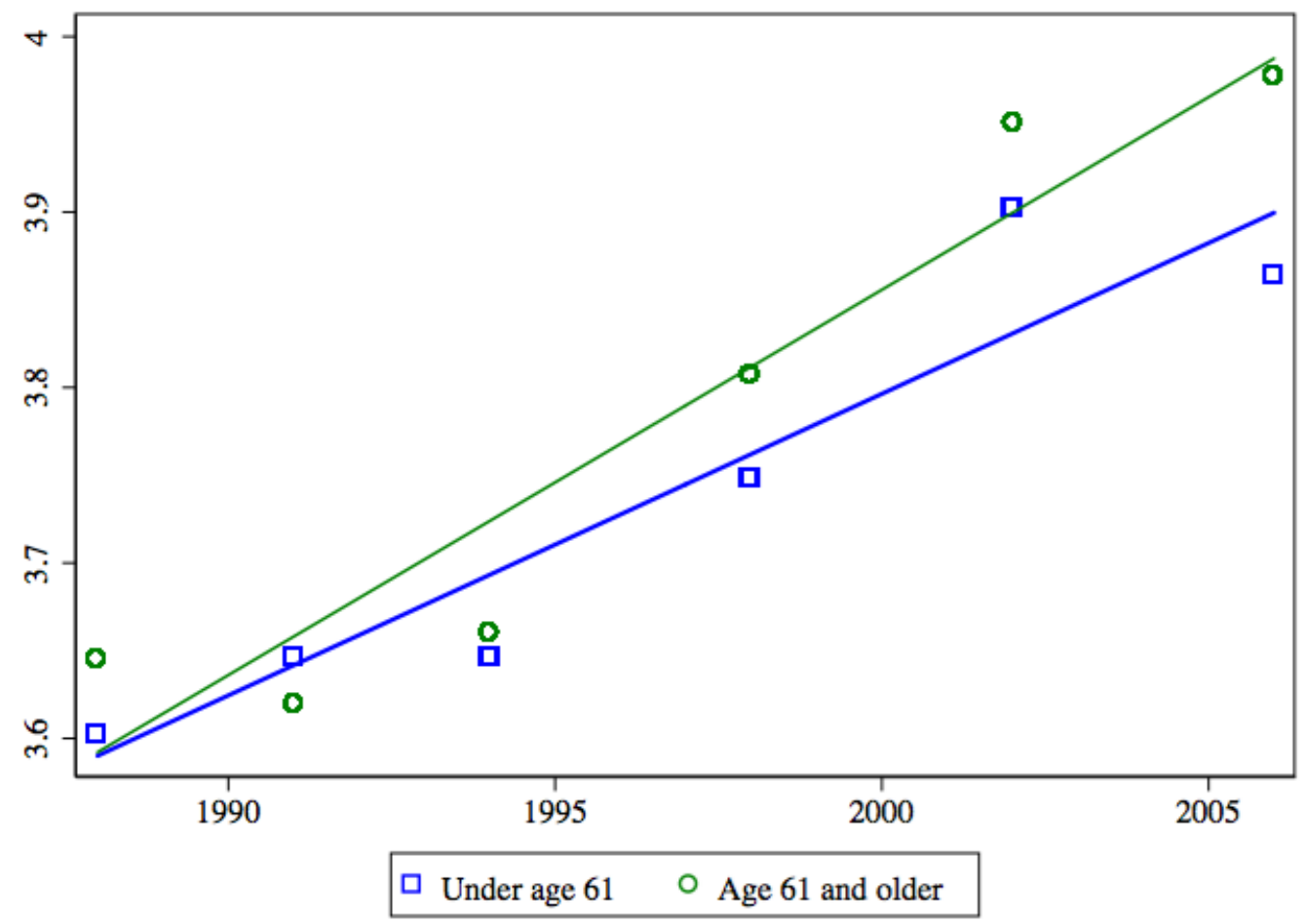

Notes: This figure depicts responses since 1988 in the Swedish National Election Studies (SNES) Program on whether the government should reduce income differences. The graph uses the v121, v130, v131, v142, v153 and v406 variables from the SNES in the years presented above, respectively (though subtracts it from six so that it is increasing in support for government activism). 


\section{Online Appendix A. Supplementary figures and tables noted in the text}

Online Appendix Figure A.1: The six "cut points" generated from ordered probit estimate in Online Appendix Table A.5 col. (1)

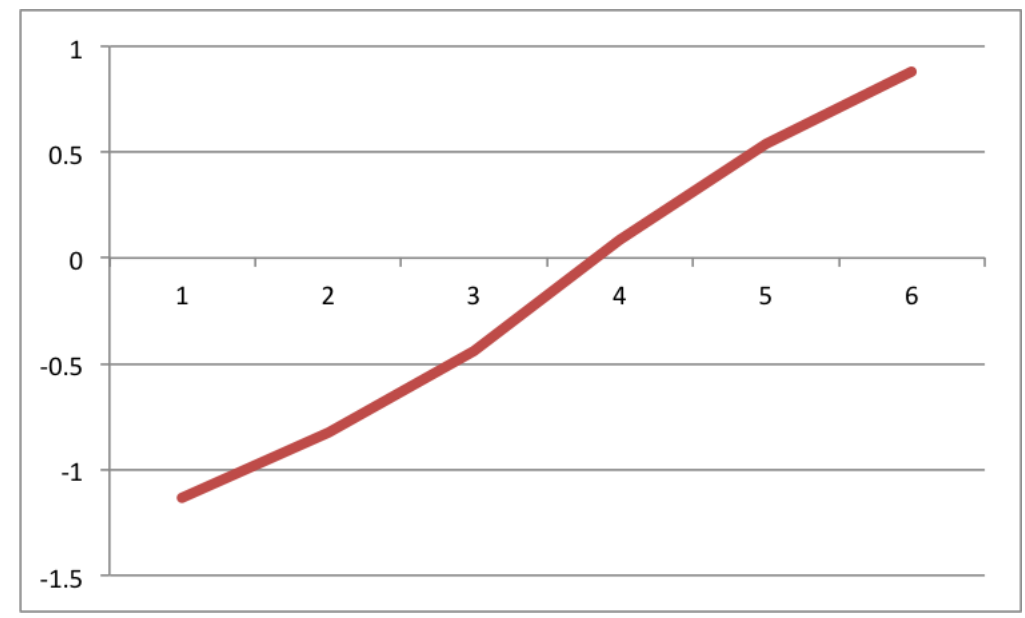

Notes: There are seven categories for the main "redistribution" outcome variable, generating six ordered probit "cut-points" (with $-\infty$ and $+\infty$ serving as endpoints). The generated cut-points are graphed on the y-axis. 


\section{Redistributive views by age in other countries (additional outcomes not shown in main draft)}

Online Appendix Figure A.2: View regarding gap between high and low incomes, elderly versus others, British Social Attitudes survey

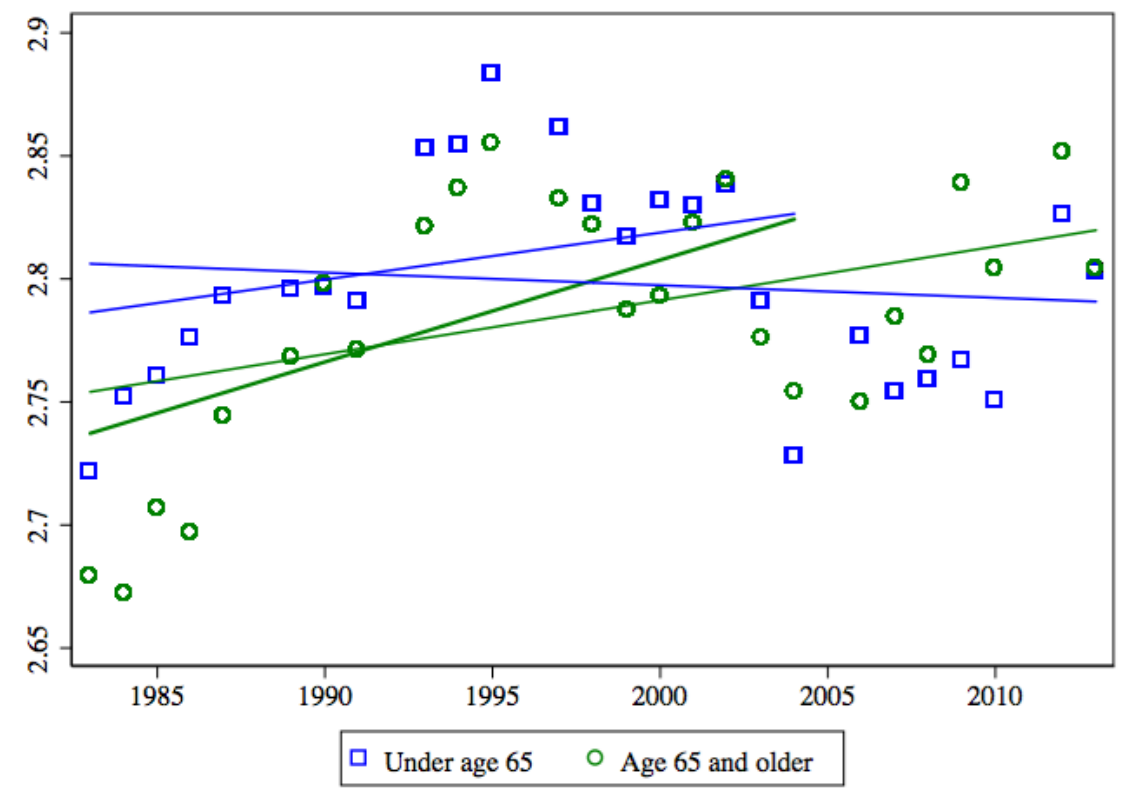

Notes: This figure depicts responses since 1983 in the British Social Attitudes (BSA) on the gap between high and low incomes. The graph uses the incomgap variable from the BSA (though subtracts it from four so that it is increasing in the size of the perceived gap). The shorter line depicts the trend line from 1985 to 2004 only. 
Online Appendix Figure A.3: Agreement that government should redistribute income, elderly versus others, British Social Attitudes survey

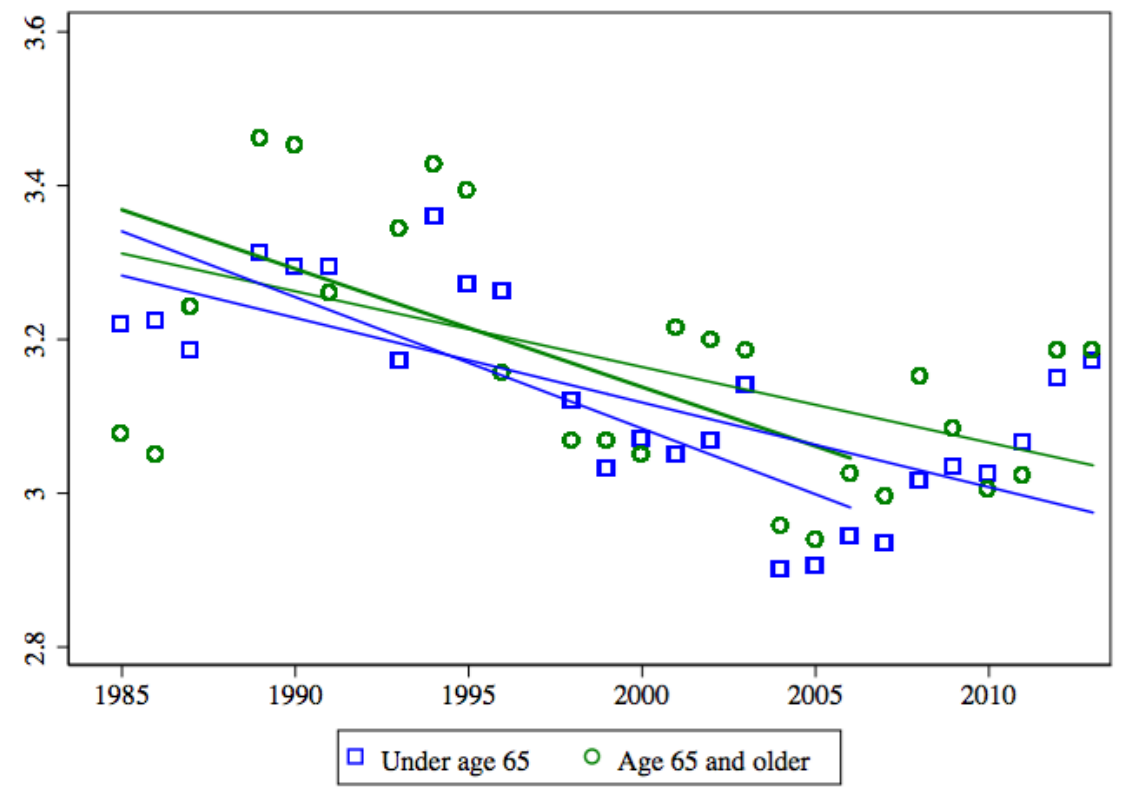

Notes: This figure depicts responses since 1985 in the British Social Attitudes (BSA) on the support for government redistribution of income. The graph uses the redistrb variable from the BSA (though subtracts it from six so that it is increasing in support for government activism). The shorter line depicts the trend line from 1985 to 2004 only. 
Online Appendix Figure A.4: Agreement that income should not be based solely on individual achievement, everybody should have what they need for a decent life, elderly versus others, German General Social Survey (ALLBUS)

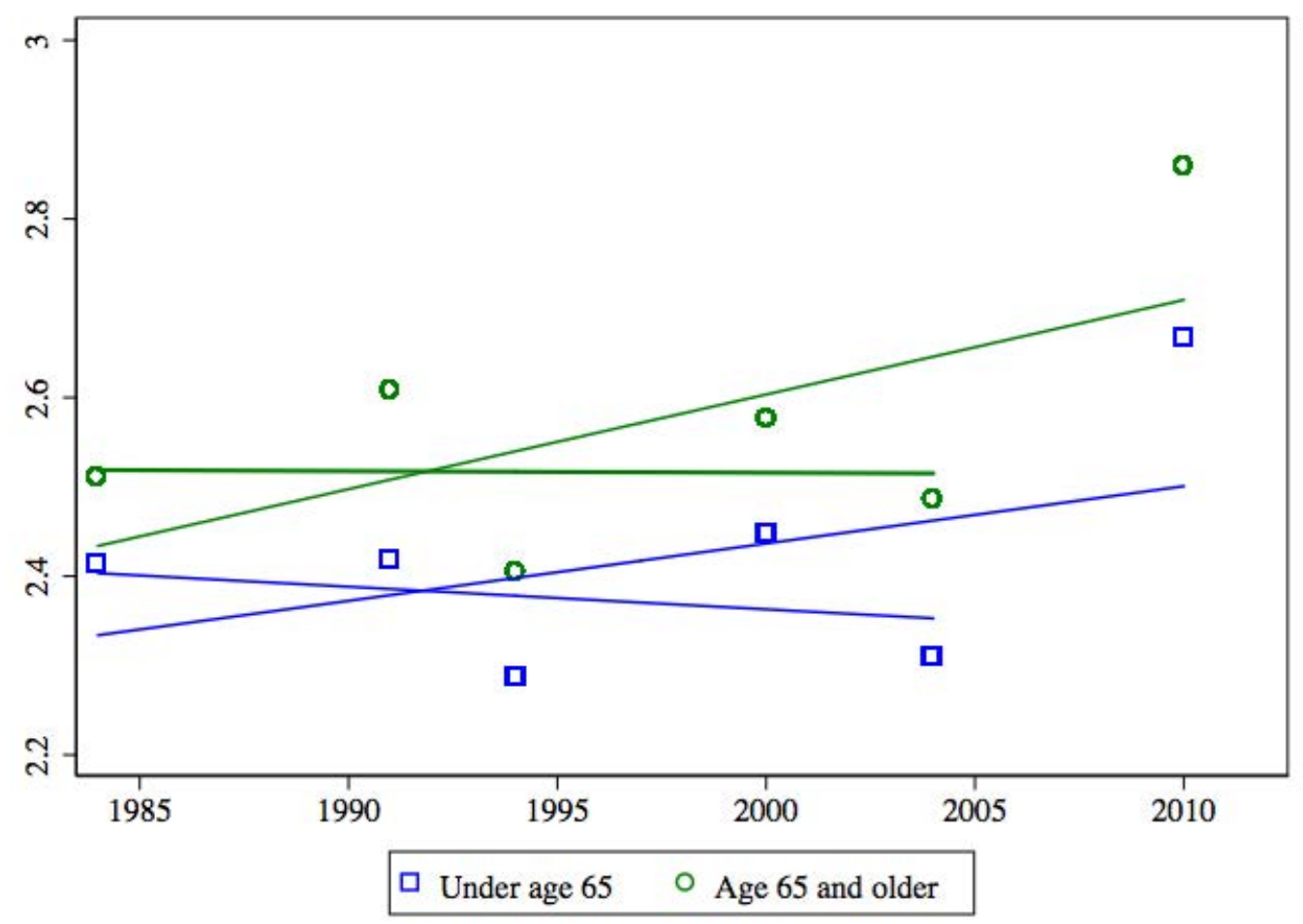

Notes: This figure depicts responses since 1984 in the German General Social Survey (ALLBUS) on the link between income and individual achievement. The graph uses the V205 variable from the ALLBUS (though subtracts it from five so that it is increasing in support for government activism). The shorter line depicts the trend line from 1984 to 2004 only. 
Online Appendix Figure A.5: Disagreement that differences in income are needed as incentive for individual achievement, elderly versus others, German General Social Survey (ALLBUS)

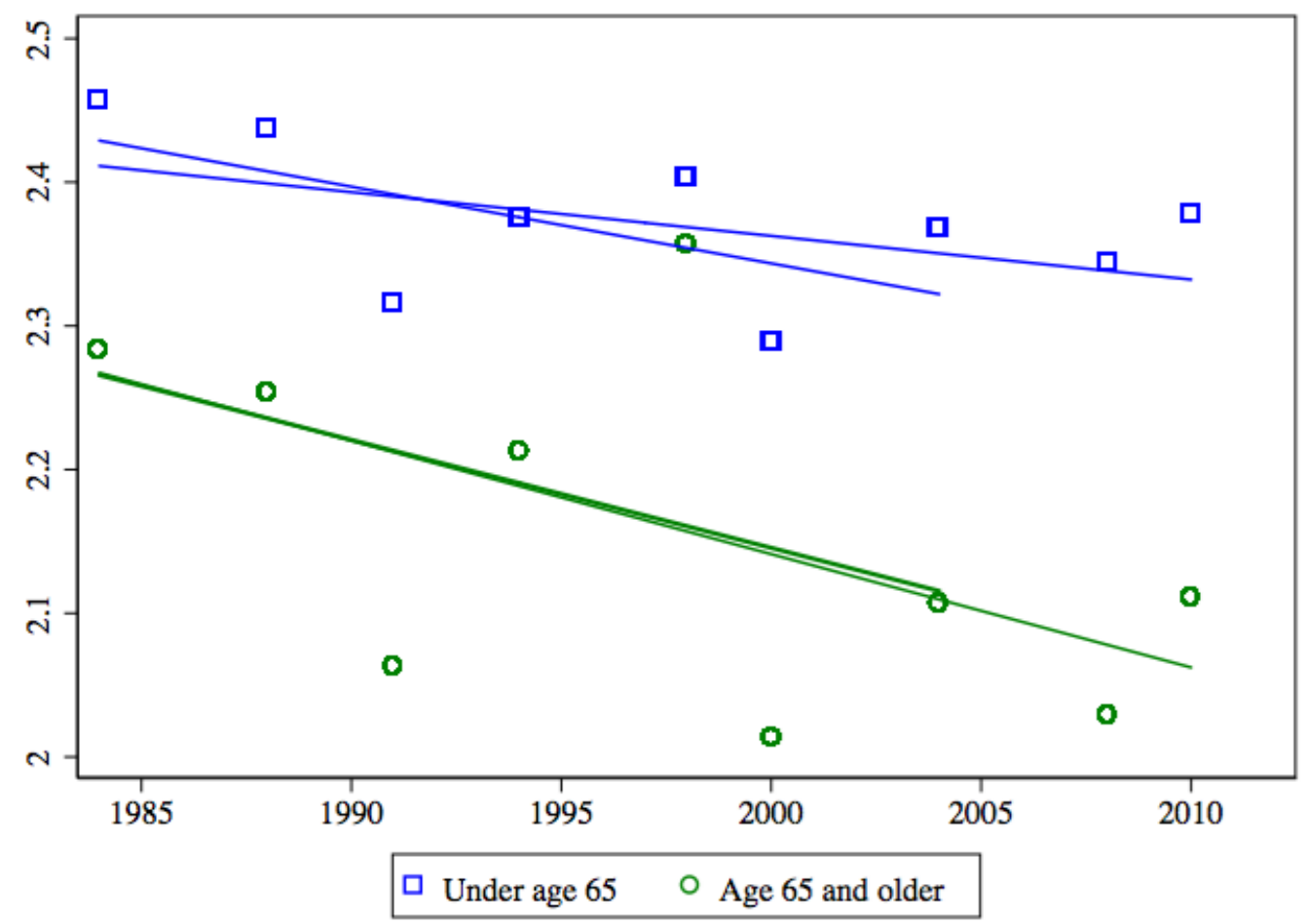

Notes: This figure depicts responses since 1984 in the German General Social Survey (ALLBUS) on whether income differences are needed as an incentive for individual achievement. The graph uses the V206 variable from the ALLBUS (though subtracts it from five so that it is increasing in disagreement with the statement). The shorter line depicts the trend line from 1984 to 2004 only. 
Online Appendix Figure A.6: Agreement that state should ensure decent income, German General Social Survey (ALLBUS), excluding East German residents

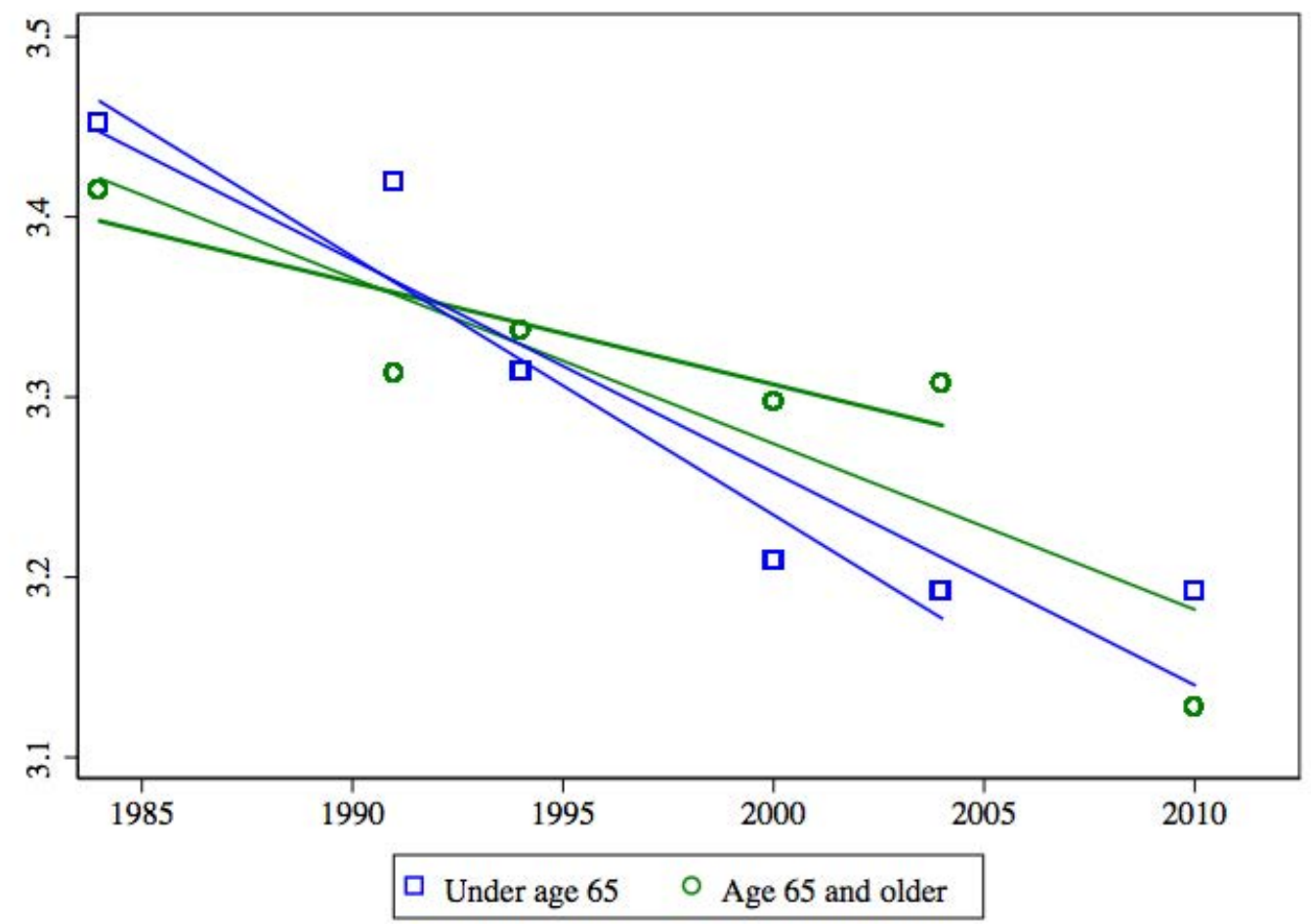

Notes: This figure depicts responses since 1984 in the German General Social Survey (ALLBUS) on whether income differences are needed as an incentive for individual achievement. Respondents included in the figure reside in the territory of the old Federal Republic (including West Berlin) at the time of the interview $(V 5=1)$. The graph uses the V206 variable from the ALLBUS (though subtracts it from five so that it is increasing in disagreement with the statement). The shorter line depicts the trend line from 1984 to 2004 only. 


\section{Robustness of results in Table 1 (GSS)}

Online Appendix Table A.1: Main black and elderly results, allowing effects of control variables to vary linearly with time

\begin{tabular}{|c|c|c|c|c|}
\hline & \multicolumn{4}{|c|}{ Reduce inc. diffs } \\
\hline & (1) & $(2)$ & $(3)$ & $(4)$ \\
\hline Elderly x & $-1.995^{* * *}$ & & $-1.910^{* * *}$ & $-1.571^{* * *}$ \\
\hline$($ Year-1975)/100 & {$[0.401]$} & & {$[0.386]$} & {$[0.507]$} \\
\hline Black x & & $-1.423^{* * *}$ & $-1.439^{* * *}$ & $-1.827^{* * *}$ \\
\hline$($ Year-1975)/100 & & {$[0.414]$} & {$[0.428]$} & {$[0.590]$} \\
\hline College $\mathrm{x}$ & & & & $1.044^{*}$ \\
\hline$($ Year-1975)/100 & & & & {$[0.499]$} \\
\hline Top inc. quintile $\mathrm{x}$ & & & & 0.581 \\
\hline$($ Year-1975)/100 & & & & {$[0.455]$} \\
\hline Female $\mathrm{x}$ & & & & -0.0234 \\
\hline$($ Year-1975)/100 & & & & {$[0.362]$} \\
\hline Mean, dept. var. & 4.251 & 4.252 & 4.251 & 4.256 \\
\hline Observations & 24388 & 24463 & 24388 & 21875 \\
\hline
\end{tabular}

Notes: Year fixed effects are included in all regressions. The main effects of any interaction variable are included in the regression but are not reported. ${ }^{*} p<0.1,{ }^{* *} p<0.05,{ }^{* * *} p<0.01$ 
Online Appendix Table A.2: Do income measures explain redistribution trends? (Extending sample through 2012)

\begin{tabular}{|c|c|c|c|c|c|c|c|c|}
\hline & \multicolumn{8}{|c|}{ Reduce inc. diffs (1-7) } \\
\hline & (1) & (2) & (3) & (4) & (5) & (6) & (7) & (8) \\
\hline $\begin{array}{l}\text { Elderly x } \\
(\text { Year-1975)/100 }\end{array}$ & $\begin{array}{c}-2.138^{* * *} \\
{[0.318]}\end{array}$ & $\begin{array}{c}-1.971^{* * *} \\
{[0.329]}\end{array}$ & $\begin{array}{c}-1.490^{* * *} \\
{[0.315]}\end{array}$ & $\begin{array}{c}-1.829^{* * *} \\
{[0.355]}\end{array}$ & & & & \\
\hline $\begin{array}{l}\text { Black x } \\
(\text { Year-1975)/100 }\end{array}$ & & & & & $\begin{array}{l}-0.668 \\
{[0.589]}\end{array}$ & $\begin{array}{l}-0.800 \\
{[0.525]}\end{array}$ & $\begin{array}{l}-0.682 \\
{[0.590]}\end{array}$ & $\begin{array}{l}-0.530 \\
{[0.605]}\end{array}$ \\
\hline Mean, dept. var. & 4.253 & 4.254 & 4.253 & 4.253 & 4.254 & 4.256 & 4.254 & 4.254 \\
\hline Scaled effect (SD) & -1.090 & -1.005 & -0.760 & -0.933 & -0.340 & -0.408 & -0.348 & -0.270 \\
\hline Scaled effect (party) & -1.845 & -1.705 & -1.286 & -1.578 & -0.576 & -0.691 & -0.588 & -0.458 \\
\hline Income covar? & No & Yes & No & No & No & Yes & No & No \\
\hline Educ. covars? & No & No & Yes & No & No & No & Yes & No \\
\hline Relative covars? & No & No & No & Yes & No & No & No & Yes \\
\hline Share explained & & .0779946 & .3029018 & .1445914 & & -.1981527 & -.0215247 & .2053602 \\
\hline Observations & 28310 & 28144 & 28310 & 28310 & 28395 & 28223 & 28395 & 28395 \\
\hline
\end{tabular}


Online Appendix Table A.3: Do income measures explain redistribution trends? (Additional interactions)

\begin{tabular}{|c|c|c|c|c|c|c|c|c|}
\hline & \multicolumn{8}{|c|}{ Reduce inc. diffs (1-7) } \\
\hline & (1) & $(2)$ & $(3)$ & (4) & $(5)$ & (6) & (7) & (8) \\
\hline $\begin{array}{l}\text { Elderly x } \\
(\text { Year-1975)/100 }\end{array}$ & $\begin{array}{c}-1.995^{* * *} \\
{[0.401]}\end{array}$ & $\begin{array}{c}-2.034^{* * *} \\
{[0.392]}\end{array}$ & $\begin{array}{c}-1.452^{* * *} \\
{[0.405]}\end{array}$ & $\begin{array}{c}-1.791^{* * *} \\
{[0.388]}\end{array}$ & & & & \\
\hline $\begin{array}{l}\text { Black x } \\
(\text { Year-1975)/100 }\end{array}$ & & & & & $\begin{array}{c}-1.423^{* * *} \\
{[0.414]}\end{array}$ & $\begin{array}{c}-1.737^{* * *} \\
{[0.480]}\end{array}$ & $\begin{array}{c}-1.821^{* * *} \\
{[0.450]}\end{array}$ & $\begin{array}{c}-1.495^{* * *} \\
{[0.374]}\end{array}$ \\
\hline Mean, dept. var. & 4.251 & 4.252 & 4.251 & 4.251 & 4.252 & 4.254 & 4.252 & 4.252 \\
\hline Scaled effect & -1.846 & -1.882 & -1.343 & -1.658 & -1.316 & -1.605 & -1.683 & -1.382 \\
\hline Income covar? & No & Yes & No & No & No & Yes & No & No \\
\hline Educ. covars? & No & No & Yes & No & No & No & Yes & No \\
\hline Relative covars? & No & No & No & Yes & No & No & No & Yes \\
\hline Share explained & & -.0197095 & .2722932 & .1018803 & & -.2199206 & -.2789428 & -.0500543 \\
\hline Observations & 24388 & 24260 & 24388 & 24388 & 24463 & 24331 & 24463 & 24463 \\
\hline
\end{tabular}

See notes for Table 1. In cols. (2) through (4) and (6) through (8), each of the additional controls is interacted with the group of interest. For example, in col. (3), each of the education fixed effects enters the equation both in levels and interacted with the elderly variable.

${ }^{*} p<0.1,{ }^{* *} p<0.05,{ }^{* * *} p<0.01$ 
Online Appendix Table A.4: Do income measures explain redistribution trends? (Dropping obs. with missing income values)

\begin{tabular}{|c|c|c|c|c|c|c|c|c|}
\hline & \multicolumn{8}{|c|}{ Reduce inc. diffs (1-7) } \\
\hline & $(1)$ & $(2)$ & $(3)$ & $(4)$ & $(5)$ & (6) & $(7)$ & $(8)$ \\
\hline $\begin{array}{l}\text { Elderly x } \\
(\text { Year-1975)/100 }\end{array}$ & $\begin{array}{c}-1.852^{* * *} \\
{[0.489]}\end{array}$ & $\begin{array}{c}-1.759^{* * *} \\
{[0.499]}\end{array}$ & $\begin{array}{c}-1.175^{* *} \\
{[0.523]}\end{array}$ & $\begin{array}{c}-1.601^{* * *} \\
{[0.518]}\end{array}$ & & & & \\
\hline $\begin{array}{l}\text { Black x } \\
(\text { Year-1975)/100 }\end{array}$ & & & & & $\begin{array}{c}-1.950^{* * *} \\
{[0.526]}\end{array}$ & $\begin{array}{c}-2.016^{* * *} \\
{[0.584]}\end{array}$ & $\begin{array}{c}-1.915^{* * *} \\
{[0.577]}\end{array}$ & $\begin{array}{c}-1.776^{* * *} \\
{[0.518]}\end{array}$ \\
\hline Mean, dept. var. & 4.254 & 4.256 & 4.254 & 4.254 & 4.256 & 4.257 & 4.256 & 4.256 \\
\hline Scaled effect (SD) & -0.953 & -0.905 & -0.605 & -0.824 & -1.004 & -1.037 & -0.986 & -0.914 \\
\hline Scaled effect (party) & -1.698 & -1.613 & -1.077 & -1.468 & -1.788 & -1.847 & -1.755 & -1.627 \\
\hline Income covar? & No & Yes & No & No & No & Yes & No & No \\
\hline Educ. covars? & No & No & Yes & No & No & No & Yes & No \\
\hline Relative covars? & No & No & No & Yes & No & No & No & Yes \\
\hline Share explained & & .0502844 & .3657529 & .135805 & & -.0334621 & .0180649 & .0896414 \\
\hline Observations & 22030 & 21902 & 22030 & 22030 & 22061 & 21929 & 22061 & 22061 \\
\hline
\end{tabular}

Online Appendix Table A.5: Do income measures explain redistribution trends? (Ordered probit)

\begin{tabular}{lcccccccc}
\hline & \multicolumn{7}{c}{ Reduce inc. diffs $(1-7)$} \\
\cline { 2 - 8 } & $(1)$ & $(2)$ & $(3)$ & $(4)$ & $(5)$ & $(6)$ & $(7)$ & $(8)$ \\
\hline Elderly x & $-1.038^{* * *}$ & $-1.021^{* * *}$ & $-0.712^{* * *}$ & $-0.921^{* * *}$ \\
$($ Year-1975)/100 & {$[0.214]$} & {$[0.212]$} & {$[0.208]$} & {$[0.216]$} & & & & \\
Black x & & & & & $-0.844^{* * *}$ & $-0.862^{* * *}$ & $-0.905^{* * *}$ & $-0.781^{* * *}$ \\
(Year-1975)/100 & & & & & {$[0.232]$} & {$[0.254]$} & {$[0.261]$} & {$[0.236]$} \\
\hline Mean, dept. var. & 4.251 & 4.252 & 4.251 & 4.251 & 4.252 & 4.254 & 4.252 & 4.252 \\
Income covar? & No & Yes & No & No & No & Yes & No & No \\
Educ. covars? & No & No & Yes & No & No & No & Yes & No \\
Relative covars? & No & No & No & Yes & No & No & No & Yes \\
Observations & 24388 & 24260 & 24388 & 24388 & 24463 & 24331 & 24463 & 24463 \\
\hline See notes for Tabl
\end{tabular}

See notes for Table $1 .{ }^{*} p<0.1,{ }^{* *} p<0.05,{ }^{* * *} p<0.01$ 
Online Appendix Table A.6: Do other policy preference explain black/elderly effect?

\begin{tabular}{|c|c|c|c|c|c|c|c|c|}
\hline & \multicolumn{8}{|c|}{ Dept. Var: Reduce inc. diffs } \\
\hline & $(1)$ & $(2)$ & (3) & $(4)$ & $(5)$ & $(6)$ & $(7)$ & (8) \\
\hline $\begin{array}{l}\text { Elderly x } \\
(\text { Year-1975)/100 }\end{array}$ & $\begin{array}{c}-2.528^{* * *} \\
{[0.425]}\end{array}$ & $\begin{array}{c}-2.505^{* * *} \\
{[0.434]}\end{array}$ & $\begin{array}{r}-2.461^{* * *} \\
{[0.365]}\end{array}$ & $\begin{array}{c}-2.347^{* * *} \\
{[0.382]}\end{array}$ & & & & \\
\hline $\begin{array}{l}\text { Black x } \\
(\text { Year-1975)/100 }\end{array}$ & & & & & $\begin{array}{r}-1.700^{* *} \\
{[0.618]}\end{array}$ & $\begin{array}{c}-1.593^{* *} \\
{[0.611]}\end{array}$ & $\begin{array}{c}-1.912^{* * *} \\
{[0.562]}\end{array}$ & $\begin{array}{c}-1.731^{* * *} \\
{[0.564]}\end{array}$ \\
\hline $\begin{array}{l}\text { Support abortion } \\
\text { rights }\end{array}$ & & $\begin{array}{c}-0.151^{* * *} \\
{[0.0503]}\end{array}$ & & & & $\begin{array}{l}-0.146^{* *} \\
{[0.0496]}\end{array}$ & & \\
\hline Homo. sex wrong & & $\begin{array}{l}-0.0287 \\
{[0.0173]}\end{array}$ & & & & $\begin{array}{c}-0.0512^{* *} \\
{[0.0174]}\end{array}$ & & \\
\hline $\begin{array}{l}\text { Support gun ownership } \\
\text { rights }\end{array}$ & & & & $\begin{array}{l}-0.515^{* * *} \\
{[0.0894]}\end{array}$ & & & & $\begin{array}{c}-0.470^{* * *} \\
{[0.0898]}\end{array}$ \\
\hline Mean, dept. var. & 4.236 & 4.236 & 4.230 & 4.230 & 4.237 & 4.237 & 4.232 & 4.232 \\
\hline Scaled effect & -2.318 & -2.296 & -2.240 & -2.136 & -1.555 & -1.457 & -1.736 & -1.572 \\
\hline Share explained & - & .0093518 & - & .0465159 & - & .0627715 & - & .0943607 \\
\hline Observations & 11588 & 11588 & 12378 & 12378 & 11618 & 11618 & 12415 & 12415 \\
\hline
\end{tabular}




\section{Online Appendix B. Summary of Surveys Considered for Inter- national Evidence}

To compare our results for the US to other countries, we conducted a comprehensive search for comparable datasets from similar, developed countries. Our universe was the 17 OECD nations with the highest per capita income in 2012 according to The World Bank. These nations are in order: Norway, Switzerland, Luxembourg, Australia, Denmark, Sweden, (the United States), Canada, Austria, the Netherlands, Finland, Japan, Germany, Belgium, Iceland, France and the United Kingdom. Additionally, we considered a number of cross-national surveys, which sample across multiple countries in each wave.

If a survey asked a consistently phrased and measured question regarding redistributive preferences over at least a ten year period prior to 2006, we included the country in our international analyses. We found that 3 national surveys and none of the cross-national

surveys met our criteria for inclusion. The tables on the next several pages summarize the results of this search. 
Online Appendix Table B.1: Summary of international surveys

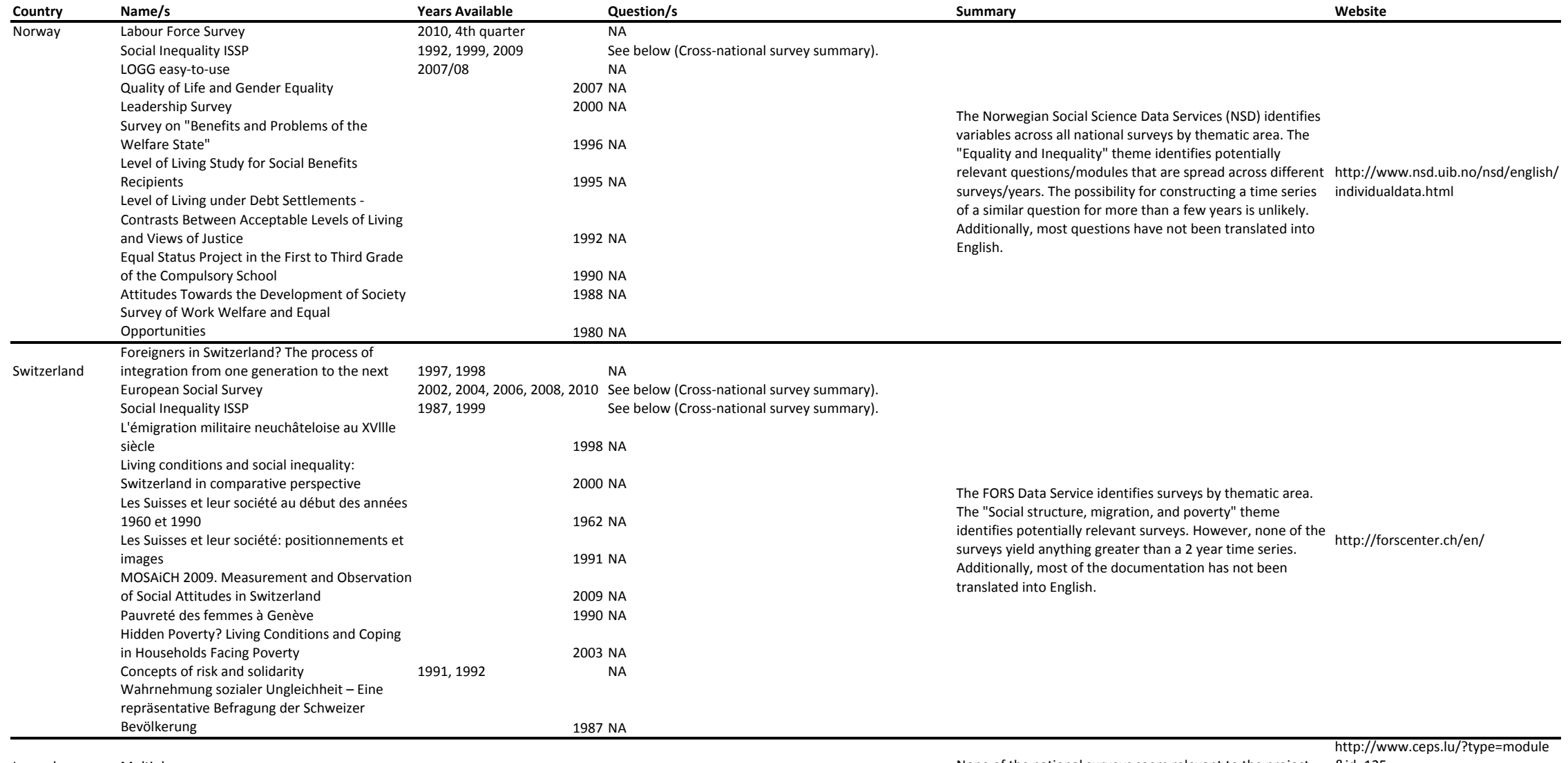


Online Appendix Table B.1: Summary of international surveys (cont'd)

\begin{tabular}{|c|c|c|c|c|c|}
\hline Country & Name/s & Years Available & Question/s & Summary & Website \\
\hline Australia & $\begin{array}{l}\text { National Social Science Survey (NSSS) } \\
\text { Australian Survey of Social Attitudes (AuSSA) }\end{array}$ & $\begin{array}{l}\text { 1984/85, 1986/87, 1986/87, } \\
\text { 1989/90, 1993, 1994, 1995/96 } \\
2003,2005\end{array}$ & $\begin{array}{l}\text { Government should reduce income differences ( } 4,5,7 \\
\text { pt scales vary by year) } \\
\text { There is too much of a difference between rich and } \\
\text { poor in this country (5pt scale), } \\
\text { Income and wealth should be redistributed toward } \\
\text { ordinary working people (5pt scale) } \\
\text { Government should redistribute } \\
\text { income from the better-off to those } \\
\text { who are less well-off (5pt scale), } \\
\text { Ordinary working people do not } \\
\text { get their fair share of the nation's } \\
\text { wealth ( } 5 \text { pt scale) } \\
\text { Reduce income differences between the rich and the } \\
\text { poor (4pt scale) } \\
\text { Thinking of income levels generally in Australia today, } \\
\text { would you say that the gap between those with high } \\
\text { incomes and those with low incomes is...? (5pt scale), } \\
\text { Differences in income in Australia are too large (5pt } \\
\text { scale) } \\
\text { It is the responsibility of government to reduce the } \\
\text { differences in income between people with high } \\
\text { incomes and those with low incomes ( } 5 \text { pt scale) } \\
\text { It is the responsibility of government to reduce the } \\
\text { differences in income between people with high } \\
\text { incomes and those with low incomes ( } 5 \text { pt scale) }\end{array}$ & $\begin{array}{l}\text { The NSSS has been conducted between } 1984 \text { and } 2001 . \\
\text { Questions measuring support for redistribution and attitudes } \\
\text { toward inequality have been asked in each wave. Data } \\
\text { between } 1997-2001 \text { is unavailable from the Australian Data } \\
\text { Archive. } \\
\text { The AuSSA is the current survey of social and political } \\
\text { attitudes. Every wave through } 2011 \text { has asked questions } \\
\text { measuring support for redistribution. } \\
\text { The unavailable data between } 1997 \text { and 2006, and varying } \\
\text { response scales used to measure key redistributive } \\
\text { preferences make time series analyses inappropriate for this } \\
\text { project. }\end{array}$ & $\begin{array}{l}\text { http://ada.edu.au/social- } \\
\text { science/aussa }\end{array}$ \\
\hline
\end{tabular}


Online Appendix Table B.1: Summary of international surveys (cont'd)

Country

Name/s

Attitudes to development aid and environment

Denmark

Attitudes to the welfare state

Contemporary Patterns of Social Differentiation

- The Case of Aalborg

Danish attitudes towards immigrants and

refugees

Danish Electorate Studies

Danish Gallup Omnibus Data

Danish Longitudinal Survey of Youth - Children

(DLSY-C), Children and Parents

Danish Omnibus Survey

Employments in Scientific Positions at

Universities

Eurobarometer

European Social Survey

Female Clergymen: Working Conditions and Co-
Operation
Years Available

Question/s

2002 NA

2004 NA

2002 NA

1987,1988 NA

2010 NA

1987,1997

$995 / 96$

NA

Social Inequality ISSP

Language Proficiency

Language Understanding as Source of Error in

Surveys, 1996: The Danes' Living Conditions and

Attitudes, II

Materially and Socially Badly Situated Families

Municipality size and local democracy

(Denmark)

Observa Political Index Polls

Political Values in Funen
Refugees in Denmark

Scandinavian Welfare Survey

Scandinavian Welfare su

Socilization and Politica Participation of Young

People

Socially Afflicted Children, Young People and

Families

Sport, exercise and everyday life

The development of a sustainable consumption

pattern in Denmark

The populations living conditions

The Scientific Staff at the Danish Universities

They have made their bed, now they must lie

needy and the welfare state
1976, 1987, 1981

2006, 2008, 2010, 2012

$1987,1992,1999,2009$

1996 NA

See below (Cross-national survey summary). see below (Cross-national survey summary).

\section{$1989 \mathrm{NA}$} $1996 \mathrm{NA}$

1996 NA

$1988 \mathrm{NA}$

$2001 \mathrm{NA}$

NA
1977 NA

1972 NA

NA

1979 NA

1996 NA

1999 NA

NA

2000 NA

2007-10
Summary

Website

The Danish Data Archive identifies variables across all

national surveys by thematic area. The "Social Stratification

and Groupings - Equality and Inequality" theme identifies

potentially relevant questions/modules that are spread

across different surveys/years. The possibility for

http://samfund.dda.dk/dda/default- 
Online Appendix Table B.1: Summary of international surveys (cont'd)

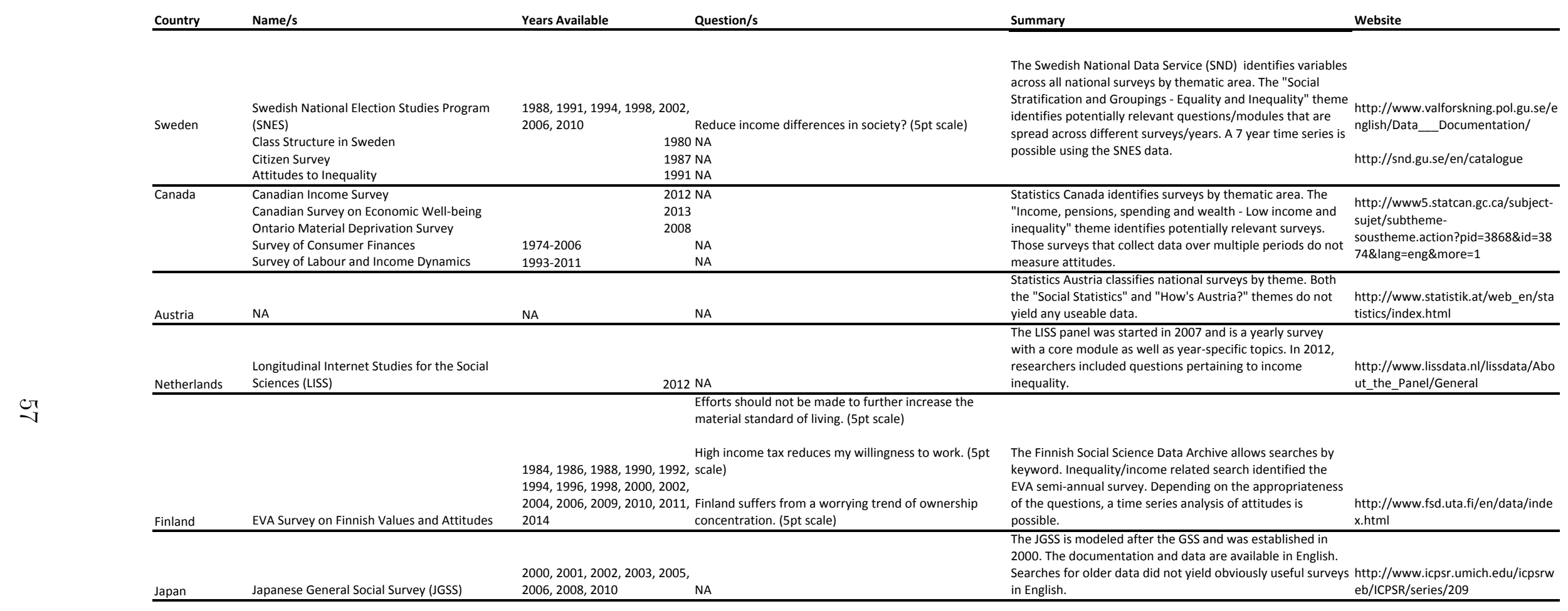


Online Appendix Table B.1: Summary of international surveys (cont'd)

\begin{tabular}{|c|c|c|c|c|c|}
\hline Country & Name/s & Years Available & Question/s & Summary & Website \\
\hline Germany & German General Social Survey (ALLBUS) & $\begin{array}{l}1984,1991,1994,2000,2004, \\
2010 \\
1984,1991,1994,2000,2004, \\
2010 \\
1984,1988,1991,1994,1998, \\
2000,2004,2008,2010\end{array}$ & $\begin{array}{l}\text { The state must ensure that people can live on a decent } \\
\text { income, even in illness, hardship, unemployment and } \\
\text { old age (4pt scale) } \\
\text { Income should not be based solely on individual } \\
\text { achievement. Instead, everybody should have what } \\
\text { they and their family need for a decent life ( } 4 \mathrm{pt} \text { scale) } \\
\text { Only when differences in income and in social standing } \\
\text { are large enough, is there an incentive for individual } \\
\text { achievement (4pt scale) }\end{array}$ & $\begin{array}{l}\text { The German GSS allows for several time series analyses of } \\
\text { attitudes. }\end{array}$ & http://www.gesis.org/en/allbus \\
\hline Belgium & $\mathrm{NA}$ & NA & $\mathrm{NA}$ & $\begin{array}{l}\text { Statistics Belgium provides access to national surveys. None } \\
\text { of the surveys listed appear relevant. } \\
\text { The Interuniversity Pole Public Policy and Opinion (PIOP) } \\
\text { conducts the General Election Study Belgium. The survey was } \\
\text { conducted in } 1991,1995,1999 \text {, and } 2003 \text {. It is unclear } \\
\text { whether any questions asked are relevant. }\end{array}$ & $\begin{array}{l}\text { http://statbel.fgov.be/en/statistics/ } \\
\text { surveys-methodology/surveys/ } \\
\text { http:///bdq.reseau- } \\
\text { quetelet.cnrs.fr/en/Study_details/2 } \\
78\end{array}$ \\
\hline Iceland & $\mathrm{NA}$ & NA & NA & $\begin{array}{l}\text { NA } \\
\text { The French Data Service (Reseau Quetelet) states that } \\
\text { French studies are not translated. }\end{array}$ & $\begin{array}{l}\text { NA } \\
\text { http://www.reseau- } \\
\text { quetelet.cnrs.fr/spip/?lang=en }\end{array}$ \\
\hline United Kingdom & British Social Attitudes (BSA) Survey & $\begin{array}{l}1985,1986,1987,1990,1991, \\
1993,1996,1999,200,2004, \\
2006,2009,2010,2012 \\
1983-87,1989-91,1993-95, \\
\text { 1997-2004, 2006-10, 2012, } \\
\text { 2013 } \\
\text { 1985-87, 1989-91, 1993-96, } \\
1998-2013\end{array}$ & $\begin{array}{l}\text { Government should reduce income differences (5pt } \\
\text { scale) } \\
\text { Gap between high and low incomes (3pt scale) } \\
\text { Government should redistribute income (5pt scale) }\end{array}$ & $\begin{array}{l}\text { The BSA Survey allows for several time series analyses of } \\
\text { attitudes. }\end{array}$ & $\begin{array}{l}\text { http://ukdataservice.ac.uk/get- } \\
\text { data/key-data.aspx }\end{array}$ \\
\hline
\end{tabular}


Online Appendix Table B.2: Summary of international surveys (Cross-national surveys)

Cross-national Survey

World Values Survey
Years Available

Waves between 1990 and 2013
Question/s

1. Now I'd like you to tell me your views on various

issues. How would you place your views on this scale?

left; 10 mens you agrecompletely with the statement

on the right: and if your views fall somewhere in

between, you can choose any number in betwe

(Code one number for each issue):

Incomes should be made more equal

2. [Same instruction as above]

The government should take more responsibility to ensure that everyone is provided for
Summary

Website

Both questions were fielded in 3 waves between 1995 and

2007 for OECD countries of interest (those comparable to

the US).

Question 1 was asked 3 times to respondents from the US; 2

times to respondents from the UK, Sweden, and Germany.

Question 2 was asked 3 times to respondents from the US and Sweden; 2 times to respondents from the UK and Germany.

http://www.worldvaluessurvey.org/ The ISSP collaborates with national survey programs to cover certain topics. Social Inequality was the focus of 4 waves (3 waves, pre-recession).

For OECD countries of interest, the coverage is as follows:

4 Years: Australia, Austria, Germany, UK, USA

3 Years: Norway, Sweden

It is the responsibility of the government to reduce the 2 Years: Canada, France, Japan, Switzerland differences in income between people with high incomes and those with low incomes [5 pt. scale] 1. People have different views of democracy. As I read you a list, please tell me how important each of the following is in a democracy to you. A small income between rich and poor...do you think this is very important, somewhat important, not too important or

2. Now lam going to read you a list of things that may be problems in our country. As I read each one, please tell me if you think it is a very big problem, a moderately big problem, a small problem or not a problem at all Social inequality (Spring 2010 )

2 questions pertaining to redistribution are only asked in single years, post-recession. questions measuring nublic ty nields a standard battery of Union/Community. Questions relating to redistribution are few, inconsistent over time, and are only asked in special waves.
The ESS is a relatively recent survey that covers 4 premeter/hom http://www.issp.org/index.php (Y) wvs.jsp

(1)
recession years starting in 2002.

In addition, the 2008 Wave focused on Welfare Attitudes,

Using this card, please say to what extent you agree or asking a number of questions pertaining to inequality and disagree with each of the following statements The redistribution ( see:

government should take measures to reduce

http://www.europeansocialsurvey.org/data/themes.html?t= http://www.europeansocialsurvey.o welfare) 